Research Article

\title{
Experimental and Numerical Evaluation of Shear Strength of Directly and Indirectly Loaded Flanged Recycled Self-Compacted Reinforced Concrete Deep Beams
}

\author{
Thamer Hussein Amer Alhussein $(1)$ and Jamal Abdul Samad Khudhair \\ Department of Civil Engineering, College of Engineering, University of Basrah, Basrah 61004, Iraq \\ Correspondence should be addressed to Thamer Hussein Amer Alhussein; enthamer@gmail.com
}

Received 19 April 2020; Revised 27 July 2020; Accepted 4 August 2020; Published 24 August 2020

Academic Editor: Hamzeh F. Haghshenas

Copyright (c) 2020 Thamer Hussein Amer Alhussein and Jamal Abdul Samad Khudhair. This is an open access article distributed under the Creative Commons Attribution License, which permits unrestricted use, distribution, and reproduction in any medium, provided the original work is properly cited.

\begin{abstract}
Experimental and numerical investigations of the behavior of directly and indirectly loaded flanged reinforced concrete (RC) deep beams cast with self-compacted concrete (SCC) containing recycled concrete as coarse aggregate (RCA) were conducted in this research. Seventeen RC deep flanged beams were designed to fail in shear. These beams were divided into three groups: twelve indirectly loaded beams without shear reinforcement; three directly loaded beams without stirrups; and two indirectly loaded beams with vertical stirrups. These beams were also classified according to the RCA ratio and shear span-to-effective depth ( $a / d)$ ratio, which will be detailed later. The RCA ranged from $0 \%$ to $75 \%$, while the a/d ratio was taken as 1.0 , 1.35, and 1.7 . Experimental results show that the use of RCA reduces the cracking and ultimate capacities, and this finding complies with the conclusions of several research studies in the literature as will be detailed later. It was observed that beams with higher RCA exhibited higher deflection, strain, and crack width. Furthermore, by increasing the $a / d$ ratio, the ultimate load was decreased due to the lower contribution of arch action shear transfer in the beam. A web reinforcement spaced at $100 \mathrm{~mm}$ and $50 \mathrm{~mm}$ increases the ultimate load by $35 \%$ and $48 \%$, respectively. Strut and tie model (STM) presented by the American Concrete Institute (ACI) 318-14 and the American Association of State Highway and Transportation Officials (AASHTO LRFD 2012) was used to predict the ultimate shear capacity of the beams. STM predicted lower beam capacity than the experimental result. The ultimate strength calculated using ACI318-14 and AASHTO LRFD 2012 was on average 38\% and 52\% lower than the experimental data, respectively, which reflects the conservative nature of this approach. Finally, 3D finite element models were created to investigate the responses of the beams. The FE results showed very good agreement with the experimental data, where FE-predicted shear capacities were on average $9 \%$ higher than the experimental results.
\end{abstract}

\section{Introduction}

Waste materials (WM) resulting from the demolition of tremendous concrete structures that have reached the end of their lifespan have negatively impacted the environment. Concrete manufactured with WM as partial replacement of natural aggregate (NA) represents a more sustainable solution to reduce further wasting materials and to minimize the consumption of natural resources. Many researchers have efficiently used recycled aggregate (RA) from concrete waste as a partial replacement of the NA. Rahal and Alrefaei [1] experimentally investigated the effects of the usage of
RCA on the shear strength of RC beams. It is suggested that a $20 \%$ reduction is applied to the shear strength equations of conventional reinforced beams when RCA is incorporated in the concrete. Wardeh and Ghorbel [2] presented an experimental study on the shear behavior of beams without transversal reinforcement made with NA concrete and 100\% RA concrete. The experimental conclusions showed that, for the same class of compressive strength, tensile strength, and fracture energy, the shear strength of RA concrete is weaker than that of NA concrete.

Segregation in concrete structures is a major challenge, especially in elements that have dense reinforcement. 
Therefore, SCC is a reliable solution in concrete technology for this issue. The workability characteristic of SCC allows concrete to fill molds even in densely reinforced elements with no segregation under the effect of its weight. Roy et al. [3] investigated the fresh and mechanical properties of SCC using locally available materials and incorporating different water-cement ratios $(w / c)$. The experimental results revealed that both compressive and tensile strengths were increased with the reduction of the $w / c$ ratio. Revilla-Cuesta et al. [4] studied the properties of SCC with RCA, as well as related results on the fresh state (workability, rheology), the hardened state (compressive strength, splitting tensile, and flexural strength; modulus of elasticity, density, and porosity), durability (resistance to aggressive agents), longterm properties of concrete (shrinkage, creep), and structural elements manufactured with SCC containing RCA. The results confirmed that the incorporation of RCA can produce a suitable recycled aggregate self-compacted concrete (RASCC), based on careful designs essential for desired performance.

Deep beams have very significant applications in the area of engineering structures. Deep beams are structural elements loaded on one face and supported on the other face so that compression struts can develop between the loads and the supports [5]. Defining beams as deep beams is controlled by satisfying geometric and/or loading conditions.

The ACI code 318-14 has stated that a beam is considered as a deep beam when either its clear span is within four times the overall member depth or the applied concentrated load acts within a distance of two times the member depth from the face of the support [5]. Nonlinear strain distributions in deep beams are caused by sudden changes in geometry or loading. This nonlinear strain distribution is violating the assumption of linear strain distribution in slender beams, and the assumption of plane sections remains plane. In other words, shear deformations in deep beams are more significant and dominate the behavior of the element in comparison with slender beams. Therefore, the classical beam theory is no longer applied to deep beams and cannot be used to determine the internal state of stress. STM presented by the ACI code 318-14 and the AASHTO 2012 was used to predict the ultimate shear capacity of the tested beams. The STM is considerably conservative and represents lower-bound strength limit states [5, 6]. Razzaq et al. [7] presented experimental verification of STM for RC deep beams under various types of loadings. Test results indicated that each beam carried loads greater than the STM design load. In other words, the STM is conservative, which gives the designers wide flexibility. Also, finite element analysis (FEA) was used to study the behavior of deep beams under direct and indirect loading conditions, as suggested by many research studies in the literature $[2,8]$.

Although deep beams are widely used in construction projects, the evaluation of ultimate strength is still less documented and limited, with a lot of uncertainties about understanding the behavior and the failure mechanism of these elements. A limited number of research studies in the literature have been conducted to investigate the response of deep beams made with self-compacted RA concrete. Thus, this research tries to fill the gap and present a thorough study that includes an experimental, code-based, and $\mathrm{FE}$ evaluation to investigate the responses of such elements. Furthermore, studying the effect of indirect loading conditions on the response of RASCC deep beams is underdocumented even in international standards like ACI and AASHTO. Therefore, this research presents a detailed study and offers an experimentally quantified approach that can be utilized to implement the effect of indirect loading conditions on the response of deep beams. Another important feature of this research is the combination of using deep beams prepared using RCA as a partial replacement of NA and utilizing the SCC technique. This combination produces more sustainable structural elements and eliminates construction efforts.

\section{Strut and Tie Model}

Structural standards like ACI 318-14 and AASHTO LRFD (2012) have adopted the STM for predicting the strength of the deep beams in 2002 and 1994, respectively. The model idealized by a hypothesis truss, which consists of struts and ties connected at nodes. The struts represent the compression members, while the ties are the tension members. Details of this approach are thoroughly presented in ACI 318-14 and AASHTO LRFD (2012). The STM analogy for the studied beams in this research is shown in Figure 1.

In both ACI 318-14 and AASHTO LRFD 2012, it is clear that the methodology and the determination of the internal forces are the same where (1) explains the design criteria of both standards, (2) calculates nominal compressive strength of a strut, (3) determines the nominal tensile strength of a tie, and (4) gives the nominal compressive strength of a nodal zone. The main difference between these two standards is about determining the effective stress of the struts, ties, and nodes. Therefore, Table 1 shows a summary of the effective stress for each element in these codes.

According to ACI 318-14 and AASHTO LRFD 2012, the ultimate shear strength of deep beams must be greater than or equal to the factored applied shear forces as presented in

$$
\Phi F n \geq F u,
$$

where $F u$ is the largest force in that element for all load combinations considered and $F n$ is the minimum nominal strength of struts, ties, and nodes:

The nominal compressive strength of a strut, $F n_{\text {strut }}$, is calculated by

$$
F n_{\text {strut }}=f c_{\text {eff_strut }} * A c_{\text {strut }}+A s^{\prime} * f s^{\prime} .
$$
by

The nominal tensile strength of a tie, $F n_{\text {tie }}$, is calculated

$$
F n_{\text {tie }}=f y * A s_{\text {tie }}
$$

The nominal compressive strength of a nodal zone (CCC and CCT), $F n_{\text {node, }}$, is calculated by 


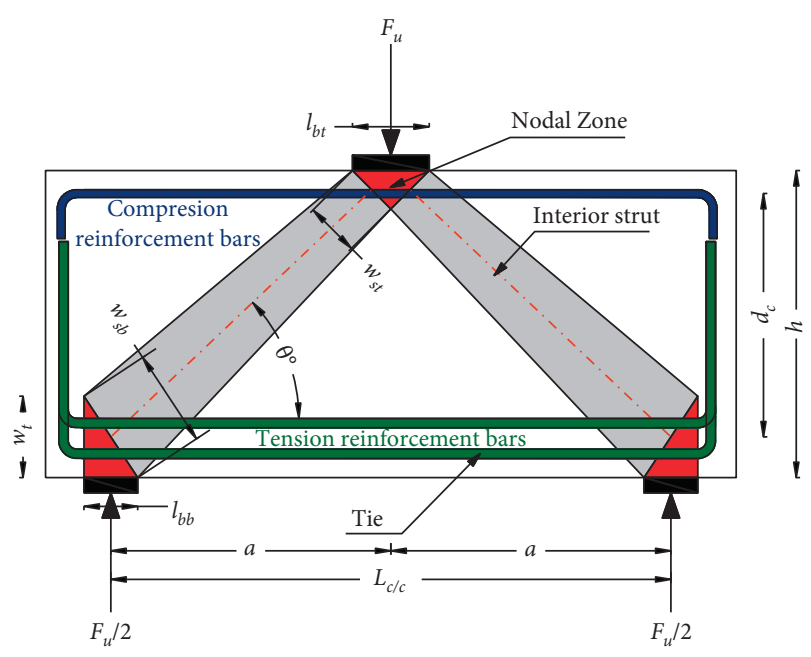

FIgURE 1: Strut and tie model (STM).

TABLE 1: Summary of effective stress for prediction ultimate strength of deep beams using STM by ACI318-14 and AASHTO LRFD 2012.

\begin{tabular}{lcc}
\hline Element & ACI 318-14 & AASHTO LRFD 2012 \\
\hline Strut & $0.85 *(0.6) * f^{\prime} c$ & $f \prime c / 0.8+170 * \varepsilon_{1} \leq 0.85 f^{\prime} c$ \\
Tie & $f y$ & $f y$ \\
CCC node & $0.85 *(1.0) * f^{\prime} c$ & $0.85 *(0.8) * f^{\prime} c$ \\
CCT node & $0.85 *(0.85) * f^{\prime} c$ & $0.75 *(0.8) * f^{\prime} c$ \\
\hline
\end{tabular}

$$
F n_{\text {node }}=f c_{\text {eff_node }} * A c_{\text {node }} .
$$

Notation: $f \mathcal{c}_{\text {eff_strut }}$ and $f \mathcal{c}_{\text {eff_node: }}$ effective stress in a strut and a node, respectively, given in Table $1 ; f c^{\prime}$ : specified compressive strength of concrete; $f y$ : specified yield strength of tensile reinforcement; $\varepsilon 1$ : principle tensile strain in concrete; CCC: node formed by three or more intersecting struts; CCT: node formed by two or more intersecting struts and a tie; $A c_{\text {strut }}$ : the cross-sectional area at the end of the strut; $A s^{\prime}$ : the area of compression reinforcement along strut length; $f s^{\prime}$ : the compression reinforcement stress at the nominal axial strength of the strut; $A s_{\text {tie }}$ : the area of tie reinforcement; $A c_{\text {node }}$ : the area of the section through the nodal zone perpendicular action line of the resultant force on the section.

The STM was used to predict the ultimate load capacity of studied deep beams. All the parameters required by STM to determine the capacity were taken from the experimental tests. However, it is important to mention that STM does not take into consideration the loading condition on the beam (i.e., direct and indirect loading), which is one of the drawbacks of this method. More details of STM results are presented later in this article.

\section{Experimental Program}

The experimental work was carried out in the laboratories of the Civil Engineering Department, University of Basra.
3.1. Materials. The properties of the materials used in the preparation of the samples are described herein. Conventional Portland cement type I that complies with the Iraqi specification number (5/1984) [9], ASTM C150 [10], C109 [11], and BS EN197 [12] was used. Physical and chemical characteristics of the coarse and fine aggregate were tested according to ASTM C33 [13]. RCA was obtained from waste materials of crushed concrete cubes. In terms of particle size distribution, the RCA grading complied with the same specification for normal coarse aggregate. Potable water was utilized for both mixing and curing of the samples. In this work, the superplasticizer used is a new generation of modified polycarboxylic ether, which is known commercially as Glenium 51. This material is compatible with all Portland cement types and free from chlorides and complies with ASTM C494 [14]. Superplasticized concrete exhibits better workability without the occurrence of segregation. It also provides enough time for mixing, casting, and finishing the final concrete surface. A limestone powder (LSP) was used to acquire the SCC by increasing the amount of cementitious material content (cement + filler). The physical properties of the constituents are presented in Table 2. Steel reinforcing deformed bars were used for the longitudinal reinforcement and stirrups. Three specimens of each size were tested according to the ASTM A615 [15]. The properties of reinforcing bars are presented in Table 3. After several trial mixes, the mix proportions shown in Table 4 were adopted in this study.

3.2. Details of the Beams. In this study, seventeen RASCC T-beams were designed to fail in shear with different $a / d$ ratios $(1.0,1.35$, and 1.7). Four mixes were prepared with different RCA replacement ratios $(0 \%, 25 \%, 50 \%$, and $75 \%)$. Out of fourteen indirectly loaded beams, twelve were prepared without web reinforcement, while two were cast with different amounts of the stirrup (spaced at $50 \mathrm{~mm}$ and $100 \mathrm{~mm}$, respectively). The other three beams, which represented the control beams, were directly loaded with the same longitudinal reinforcement details with no stirrups. All beams have the same cross section with a web thickness $b_{w}$ of $150 \mathrm{~mm}$, flange width $b_{f}$ of $450 \mathrm{~mm}$, flange depth $h_{f}$ of $100 \mathrm{~mm}$, and overall beam depth of $350 \mathrm{~mm}$. The details of the T-beams are presented in Tables 5-7 and Figures 2-4.

3.3. Concrete Mixing Procedure. The mixture was prepared using a laboratory mixer with a capacity of $0.1 \mathrm{~m}^{3}$. The same mixing procedure was maintained throughout this study to obtain the optimum effectiveness of superplasticizer and total dispersion of the particles, as suggested by some researchers in the literature $[3,16]$. This procedure is summarized as follows:

(1) Cement, limestone, and aggregate were placed and mixed for one minute.

(2) $80 \%$ of mixing water was gradually added to the mixture while maintaining the mixing process for another minute. 
TABLE 2: Physical properties of constituents.

\begin{tabular}{|c|c|c|c|c|}
\hline \multirow{2}{*}{ Test details } & \multirow{2}{*}{ Fine aggregate } & \multicolumn{2}{|c|}{ Coarse aggregate } & \multirow{2}{*}{ Limestone powder (LSP) } \\
\hline & & NCA & RCA & \\
\hline Specific gravity & 2.63 & 2.66 & 2.39 & 2.4 \\
\hline Moisture content (\%) & 1.00 & 0.55 & - & - \\
\hline Dry density $\left(\mathrm{g} / \mathrm{cm}^{3}\right)$ & 1.72 & 1.69 & - & - \\
\hline Water absorption (\%) & 1.20 & 0.84 & 5.5 & 5 \\
\hline
\end{tabular}

TABle 3: Properties of reinforcing bars.

\begin{tabular}{lccc}
\hline Bar size $(\mathrm{mm})$ & & $\begin{array}{c}\text { Test results } \\
\text { Ultimate strength }\left(\mathrm{N} / \mathrm{mm}^{2}\right)\end{array}$ & Elongation $(\%)$ \\
\hline 10 & 482 & 595 & 12 \\
12 & 516 & 647 & 13 \\
16 & 530 & 677 & 12 \\
\hline
\end{tabular}

TABle 4: Concrete mix constituents per cubic meter.

\begin{tabular}{lccccc}
\hline $\begin{array}{l}\text { Cement } \\
(\mathrm{kg})\end{array}$ & $\begin{array}{c}\text { LSP } \\
(\mathrm{kg})\end{array}$ & $\begin{array}{c}\text { Water } \\
(\mathrm{kg})\end{array}$ & $\begin{array}{c}\text { Sand } \\
(\mathrm{kg})\end{array}$ & $\begin{array}{c}\text { Gravel } \\
(\mathrm{kg})\end{array}$ & $\begin{array}{c}\text { SP } \\
(\mathrm{liter})\end{array}$ \\
\hline 379 & 162 & 167 & 755 & 944 & 5 \\
\hline
\end{tabular}

TABLE 5: Indirectly loaded beams (12 beams).

\begin{tabular}{lccccc}
\hline Beam SN & ald & \multicolumn{3}{c}{ RCA (\%) } \\
\hline G1TB & 1.0 & & & & \\
G2TB & 1.35 & 0 & 25 & 50 & 75 \\
G3TB & 1.7 & & & & \\
\hline
\end{tabular}

TABLe 6: Directly loaded beams (3 beams).

\begin{tabular}{lcc}
\hline Beam SN & $a / d$ & RCA (\%) \\
\hline DG1TB3 & 1.0 & \\
DG2TB3 & 1.35 & 50 \\
DG3TB3 & 1.7 & \\
\hline
\end{tabular}

TABLE 7: Indirectly loaded beams with stirrup (2 beams).

\begin{tabular}{lccc}
\hline Beam SN & ald & RCA (\%) & Spacing $(\mathrm{mm})$ \\
\hline G1TB3S & \multirow{2}{*}{1.0} & 50 & 100 \\
G1TB3S & & & 50 \\
\hline
\end{tabular}

(3) The superplasticizer was dissolved in the remaining $20 \%$ of mixing water and then slowly added to the mixture, while the mixing was performed for another minute.

(4) The mixing was maintained for another three minutes.

(5) The mixture was rested for three and a half minutes.

(6) Finally, the mixture was remixed for another half minute and released for executing the fresh concrete tests and casting the samples and beams.
3.4. Fresh and Hardened Properties of the Mixture. According to the European Guidelines for SCC (EFNARC, 2005), three characteristics represent the fresh SCC: filling ability, passing ability, and segregation resistance [17]. Therefore, several tests were conducted to ensure that the SCC mix meets these requirements, as shown in Figure 5 and Table 8 . The mechanical properties of the SCC mixture were determined. In particular, the compressive strength of cubes $\left(f_{\mathrm{cu}}\right)$, splitting tensile strength $\left(f_{t}\right)$, and modulus of elasticity $\left(E_{c}\right)$ were tested using three specimens for each test, and the average value was taken as presented in Table 9.

3.5. Casting of Beams. Wooden molds were used in the fabrication of the beams. The inside of the forms was lubricated before placing the reinforcement cage in the designated position. Under the influence of its weight, the concrete mixture was easily placed and leveled. The beams were moist-cured as per ACI 318-14 requirements for seven days and then stored in the laboratory for testing.

3.6. Testing of Beams. Before conducting the tests, the beams were painted to facilitate tracing the cracks. Aluminum discs with a $10 \mathrm{~mm}$ diameter and a central hole of $1.5 \mathrm{~mm}$ diameter were used to measure the strain in the concrete. The discs were positioned and attached to concrete by utilizing an epoxy resin, as shown in Figure 6. The typical arrangement, experimental setup, and loading configuration are shown in Figure 7. Universal Testing Machine (UTM) with a capacity of $2000 \mathrm{kN}$ was used to apply the load. Midspan deflection, concrete strain, and crack width were measured during the tests. Also, the inclined cracking load and ultimate load were recorded for each beam.

\section{Experimental Results and Discussion}

4.1. Crack Pattern. All tested beams failed in shear with no failure under load application or over supports. Also, the main bars were properly placed to prevent any anchorage failure. The first set of cracks that appeared due to loading comprised small flexure cracks at the bottom of the midspan 


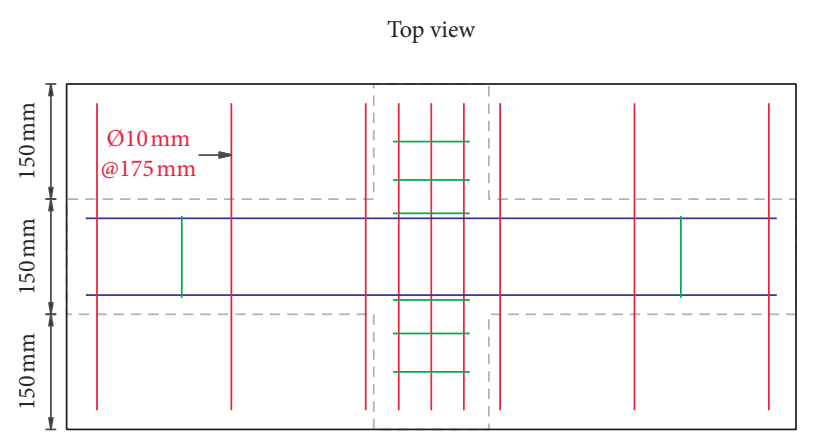

(a)

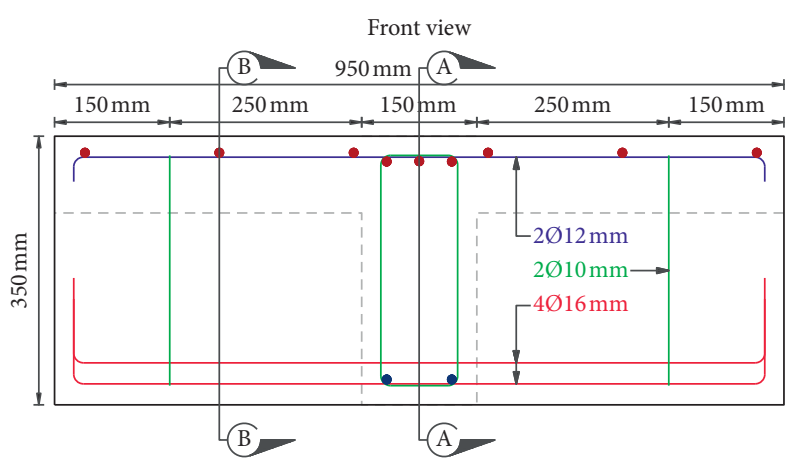

(b)

Figure 2: Indirectly loaded G1TB.

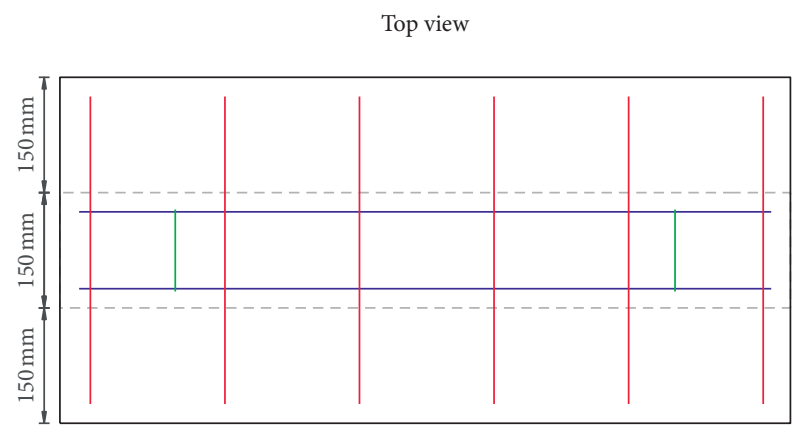

(a)

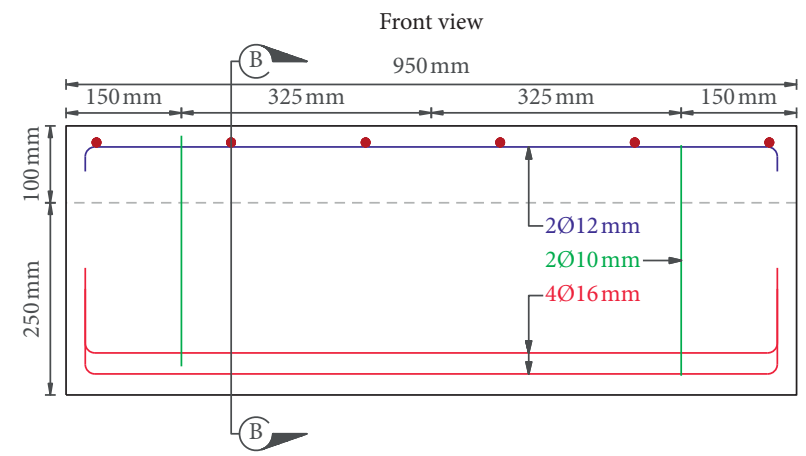

(b)

Figure 3: Directly loaded DG1TB.

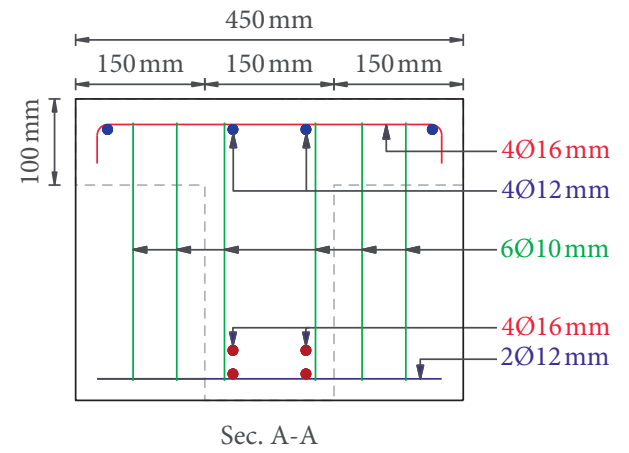

(a)

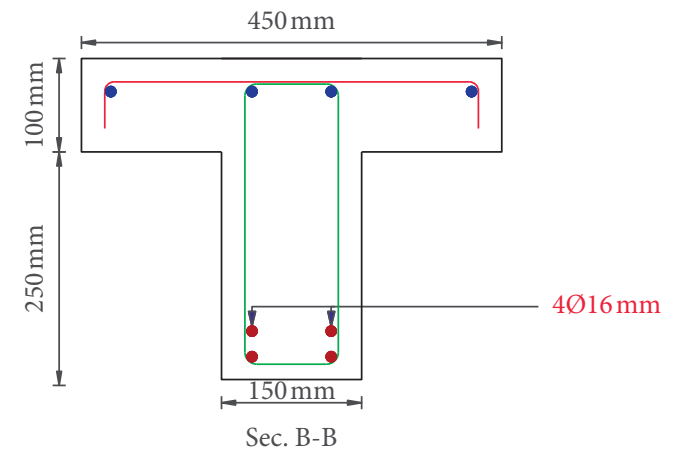

(b)

Figure 4: Cross section details.

of the beam. With further loading, an inclined crack occurred at shear zone approximately at the center of the inclined strut. Then, the main shear crack started to appear at a location close to the beam middepth (center of the strut) with the same inclination of the strut.

A further increase in the load caused a small rise in crack width and formed another inclined crack parallel to the first crack, and then the shear cracks extended toward the bottom and top of the beam, widened, and propagated up to failure in shear. For deep beams without web reinforcement, the inclined crack extended toward top and bottom with no significant increase in crack width and suddenly failed in shear. This behavior is attributed to the absence of web reinforcement, especially for deep beams with small shear span-to-effective depth $(a / d)$ ratio. This finding complies with the past research studies, which observed that RC beams with shear reinforcement fail with a diagonally cracked area, while those without shear steel fail with single 


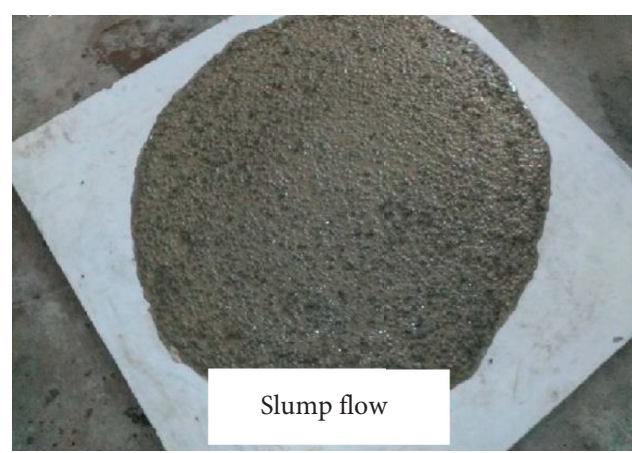

(a)

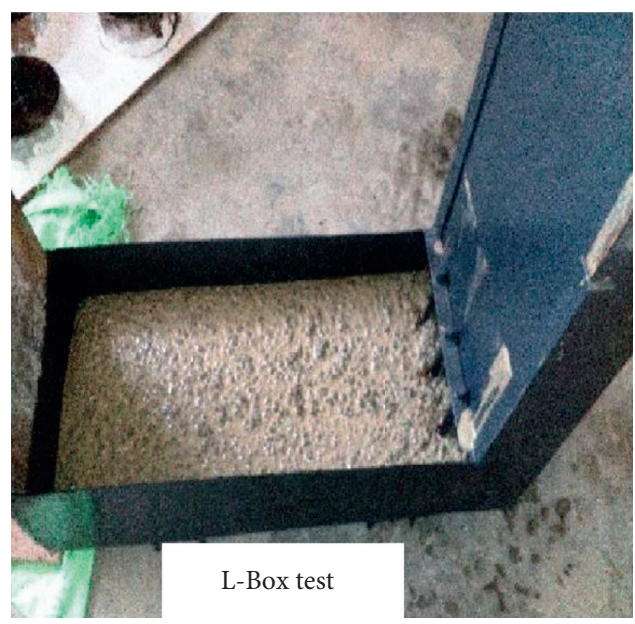

(c)

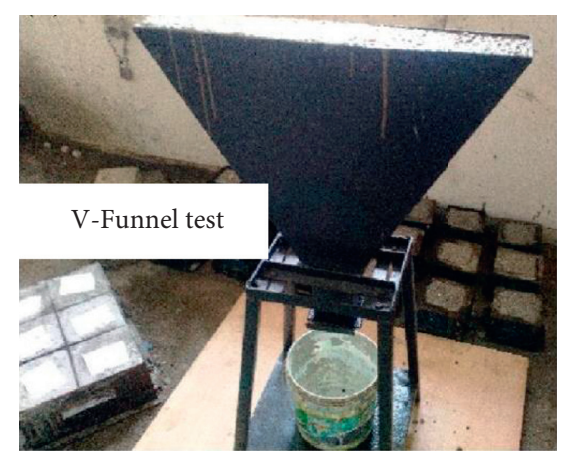

(b)

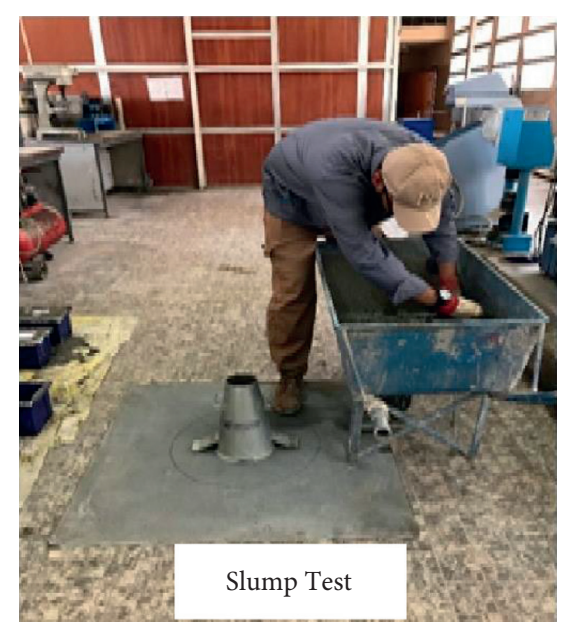

(d)

Figure 5: L-box, v-funnel, slump flow, and T50 tests.

TABle 8: Properties of fresh RASCC.

\begin{tabular}{|c|c|c|c|c|c|c|}
\hline \multirow{2}{*}{ RCA (\%) } & \multirow{2}{*}{ Slump flow (mm) } & \multicolumn{2}{|c|}{ EFNARC Guideline } & \multirow[t]{2}{*}{ T500 (sec) } & \multicolumn{2}{|c|}{ EFNARC Guideline } \\
\hline & & Min & Max & & Min & Max \\
\hline 0 & 700 & 650 & 800 & 2.66 & 2 & 5 \\
\hline 25 & 680 & 650 & 800 & 2.70 & 2 & 5 \\
\hline 50 & 660 & 650 & 800 & 2.72 & 2 & 5 \\
\hline 75 & 650 & 650 & 800 & 3.02 & 2 & 5 \\
\hline \multirow{2}{*}{ RCA (\%) } & \multirow{2}{*}{ V-funnel (sec) } & \multicolumn{2}{|c|}{ EFNARC Guideline } & \multirow{2}{*}{ L-box } & \multicolumn{2}{|c|}{ EFNARC Guideline } \\
\hline & & Min & Max & & Min & Max \\
\hline 0 & 8.27 & 8 & 12 & 0.94 & 0.8 & 1.00 \\
\hline 25 & 8.40 & 8 & 12 & 0.94 & 0.8 & 1.00 \\
\hline 50 & 8.56 & 8 & 12 & 0.93 & 0.8 & 1.00 \\
\hline 75 & 9.41 & 8 & 12 & 0.89 & 0.8 & 1.00 \\
\hline
\end{tabular}

Table 9: Properties of hardened RASCC.

\begin{tabular}{lccc}
\hline Mix with RCA $(\%)$ & Compressive strength $\left(f_{\text {cu }}\right)(\mathrm{MPa})$ & Tensile strength $\left(f_{t}\right)(\mathrm{MPa})$ & Modulus of elasticity $(E c)(\mathrm{MPa})$ \\
\hline 0 & 42.20 & 3.96 & 27510 \\
25 & 40.40 & 3.94 & 26950 \\
50 & 36.60 & 3.43 & 25740 \\
75 & 32.40 & 3.12 & 24110 \\
\hline
\end{tabular}




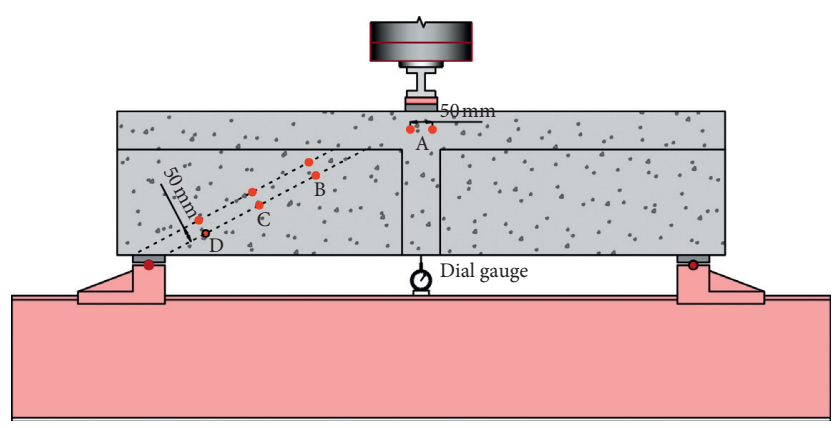

Figure 6: Arrangement of gauges in tested beams.

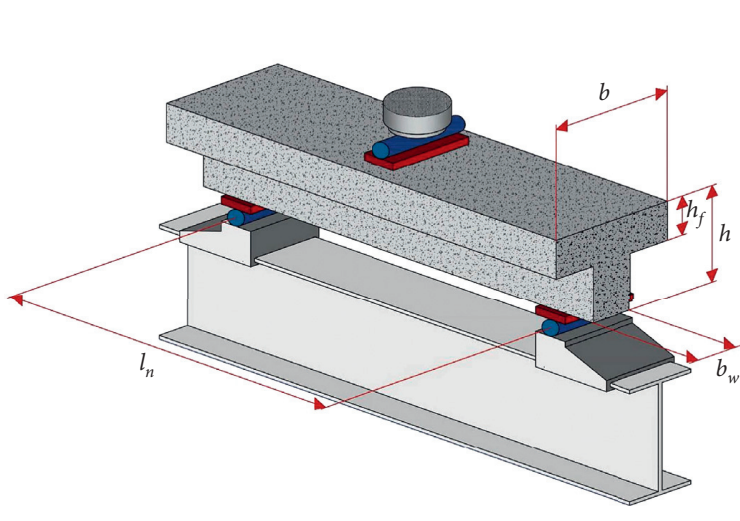

(a)

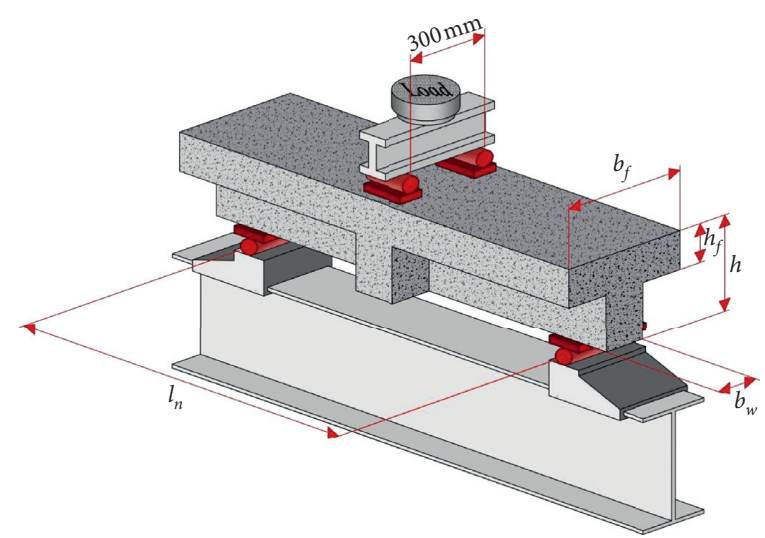

(b)

Figure 7: Instrumentation and testing procedure of the beams.

major diagonal crack $[18,19]$. The failure happened in the flanged deep beam when the major diagonal crack penetrates the flange area. The crack patterns of tested beams after failure are shown in Figures 8-10.

\subsection{Inclined Cracking and Ultimate Loads of RASCC Beams}

4.2.1. Effect of RCA Replacement Ratio. Inclined cracking and ultimate loads are listed in Tables 10-12. The inclined cracking load is defined as the load at which the first major inclined crack appears in the shear span. For the same a/d ratio, the ratios of inclined cracking to ultimate load for indirectly loaded beams ranged from $26 \%$ to $36 \%$, with an average value of $32 \%$, as illustrated in Table 10 . For beams in the first group, G1TB2, G1TB3, and G1TB4, where the replacement ratio is $25 \%, 50 \%$, and $75 \%$, respectively, the ultimate load was decreased by $14 \%, 38 \%$, and $42 \%$, respectively. For beams in the second group, G2TB2, G2TB3, and G2TB4, with replacement ratios of $25 \%, 50 \%$, and $75 \%$, respectively, the ultimate load was decreased by $21 \%, 40 \%$, and $46 \%$, respectively. For beams in the third group, G3TB2, G3TB3, and G3TB4, with replacement ratios of $25 \%, 50 \%$, and $75 \%$, respectively, the ultimate load was decreased by $2 \%, 9 \%$, and $20 \%$, respectively. The decrease in ultimate loads of the beams is attributed to the reduction in compressive strength by increasing the RCA.
Figure 11 illustrates a comparison between inclined cracking loads $\left(P_{\mathrm{cr}}\right)$ and ultimate loads $\left(P_{u}\right)$ for indirectly loaded beams with different RCA ratios. The inclined cracking load is also affected by the RCA percentage because the tensile strength of concrete decreased with the increase in RCA.

For directly loaded T-deep beam with 50\% RCA (DG1TB3, DG2TB3, and DG3TB3), the ratio of inclined cracking to ultimate loads was $31 \%, 33 \%$, and $33 \%$, respectively, as shown in Table 12. Finally, the directly loaded flanged deep beams exhibit higher load capacity than the indirectly loaded flanged deep beams because of the arch action mechanism. Indirectly loaded flanged deep beams are weaker than directly loaded deep beams; this is due to the lower arch action developed in indirectly loaded RC deep beams [20].

Based on experimental results, the average ultimate capacity of directly loaded deep beams was $23 \%$ higher than the ultimate capacity of indirectly loaded beams. This modification factor, extracted from experimental data, can be applied to the STM method to account for different loading conditions as the current STM does not account for such effect.

4.2.2. Effect of a/d Ratio. The magnitudes of the shearing stress and flexural stress affecting the inclined cracking and the subsequent failure of RC deep beams are considered as a 


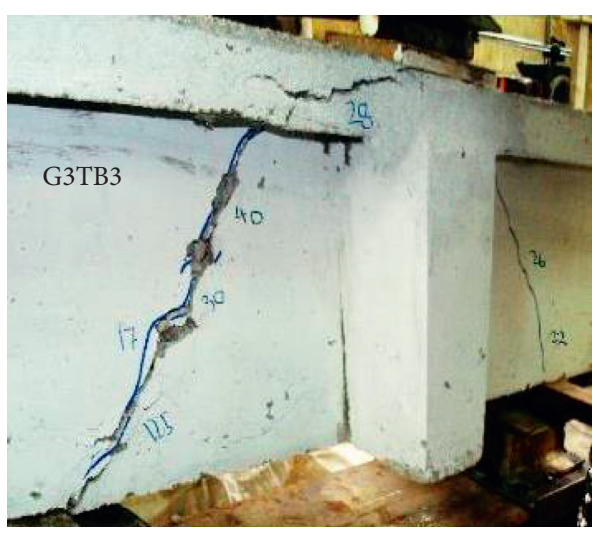

(a)

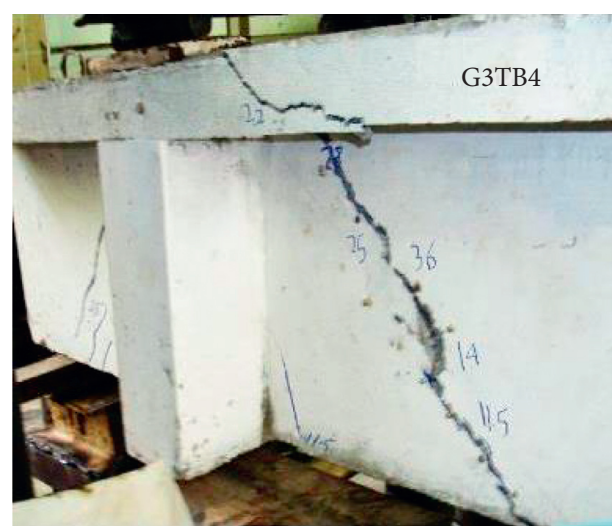

(b)

FIGURE 8: Crack pattern for indirectly loaded beams without shear reinforcement.

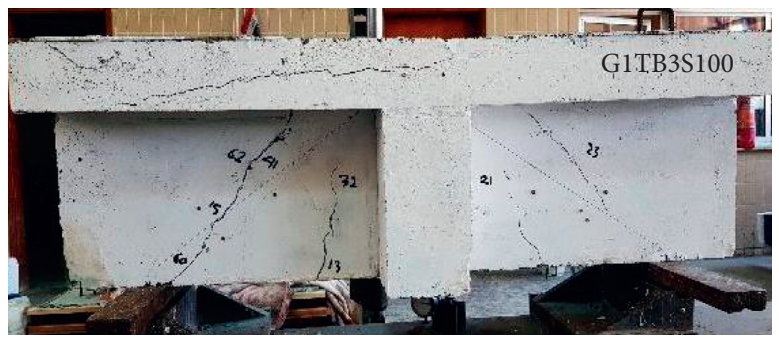

(a)

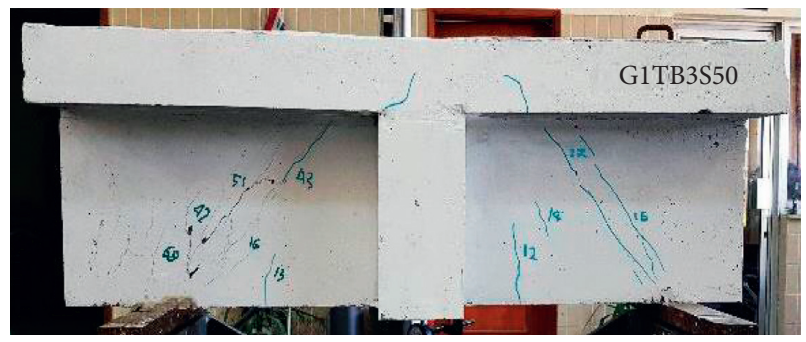

(b)

FIGURE 9: Crack pattern for indirectly loaded beams with shear reinforcement.

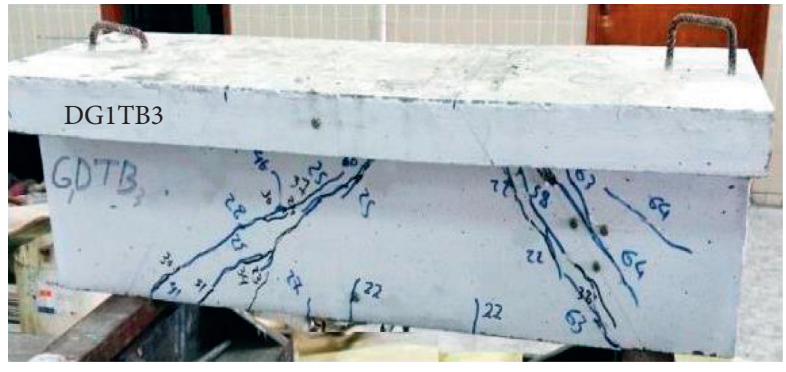

(a)

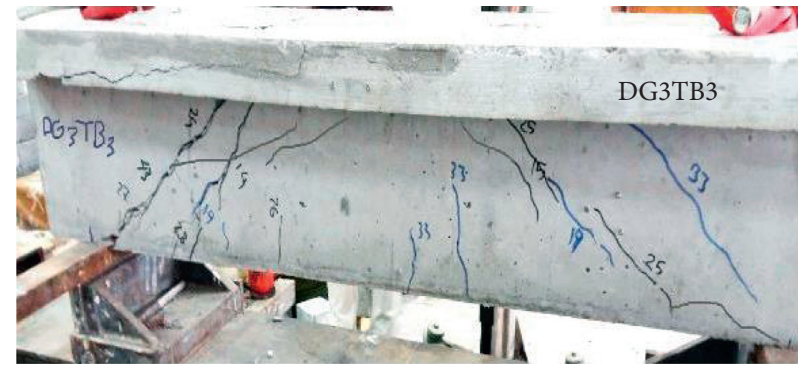

(b)

Figure 10: Crack pattern for directly loaded beam (DGTB).

function of $a / d$ ratio [8]. The distribution of stresses in the deep beams after forming inclined crack revealed a tendency toward the arch action. However, no pure arch action was formed because the force in the tension steel reinforcement is not constant along the span [21]. From Tables 10 and 12, it can be observed that the increase in the inclined cracking and ultimate loads is achieved by reducing a/d ratio.

For instance, the inclined cracking and ultimate loads of deep beams with RCA of $50 \%$ were increased by $19 \%$ and $15 \%$ for indirectly loaded beams, respectively. Meanwhile, for directly loaded beams, the inclined cracking and ultimate loads were increased by $29 \%$ and $33 \%$, respectively. Further, inclined cracking and ultimate loads for the same RCA were increased by $7 \%$ and $10 \%$ for indirectly loaded beams, while the increase was $15 \%$ and $20 \%$ for directly loaded beams when a/d ratio reduced from 1.35 to 1.0 . This increase in inclined cracking and ultimate loads is due to the higher contribution of arch action shear transfer in beams with a lower a/d ratio, which confirms other research findings in the literature $[19,22]$. Figure 12 shows a comparison between inclined cracking loads $\left(P_{\mathrm{cr}}\right)$ and ultimate loads $\left(P_{u}\right)$ 
TABLE 10: Inclined cracking and ultimate loads for indirectly loaded beams.

\begin{tabular}{|c|c|c|c|c|c|c|c|c|}
\hline \multirow[t]{2}{*}{ Beams } & \multirow[t]{2}{*}{ a/d } & \multirow[t]{2}{*}{ RCA (\%) } & \multicolumn{2}{|c|}{ Load $(\mathrm{kN})$} & \multicolumn{2}{|c|}{$\begin{array}{l}\text { Reduction due to } \\
\text { RCA (\%) }\end{array}$} & \multirow[t]{2}{*}{$P_{\mathrm{cr}} / P_{u}(\%)$} & \multirow[t]{2}{*}{ Reserved strength $P_{u}-P_{\mathrm{cr}} / P_{\mathrm{cr}}(\%)$} \\
\hline & & & Inclined cracking $P_{\mathrm{cr}}$ & Ultimate $P_{u}$ & $P_{\text {cr }}(\%)$ & $P_{u}(\%)$ & & \\
\hline G1TB1 & \multirow{4}{*}{1.0} & 0 & 210 & 740 & - & - & 28 & 252 \\
\hline G1TB2 & & 25 & 200 & 640 & 5 & 14 & 31 & 220 \\
\hline G1TB3 & & 50 & 160 & 460 & 24 & 38 & 35 & 188 \\
\hline G1TB4 & & 75 & 130 & 430 & 38 & 42 & 30 & 231 \\
\hline G2TB1 & \multirow{4}{*}{1.35} & 0 & 200 & 700 & - & - & 29 & 250 \\
\hline G2TB2 & & 25 & 200 & 550 & 0 & 21 & 36 & 175 \\
\hline G2TB3 & & 50 & 150 & 420 & 25 & 40 & 36 & 180 \\
\hline G2TB4 & & 75 & 100 & 380 & 50 & 46 & 26 & 280 \\
\hline G3TB1 & \multirow{4}{*}{1.7} & 0 & 141 & 440 & - & - & 32 & 212 \\
\hline G3TB2 & & 25 & 140 & 430 & 1 & 2 & 33 & 207 \\
\hline G3TB3 & & 50 & 135 & 400 & 4 & 9 & 34 & 196 \\
\hline G3TB4 & & 75 & 115 & 350 & 18 & 20 & 33 & 204 \\
\hline
\end{tabular}

TABLE 11: Inclined cracking and ultimate loads for indirectly loaded beams with different amount of web reinforcement.

\begin{tabular}{|c|c|c|c|c|c|c|}
\hline \multirow[b]{2}{*}{ Beams } & \multirow[b]{2}{*}{$a / d$} & \multirow[b]{2}{*}{ RCA (\%) } & \multicolumn{2}{|c|}{ Load $(\mathrm{kN})$} & \multirow[b]{2}{*}{$P_{\mathrm{cr}} / P_{u}(\%)$} & \multirow[b]{2}{*}{ Reserved strength $P_{u}-P_{\mathrm{cr}} / P_{\mathrm{cr}}(\%)$} \\
\hline & & & Inclined cracking $P_{\mathrm{cr}}$ & Ultimate $P_{u}$ & & \\
\hline G1TB3S100 & \multirow{2}{*}{1.0} & \multirow{2}{*}{50} & 165 & 620 & 27 & 276 \\
\hline G1TB3S50 & & & 170 & 680 & 25 & 300 \\
\hline
\end{tabular}

TABLE 12: Inclined cracking and ultimate loads for directly loaded RCASCC beams.

\begin{tabular}{|c|c|c|c|c|c|c|}
\hline \multirow{2}{*}{ Beams } & \multirow{2}{*}{ a/d } & \multirow{2}{*}{ RCA (\%) } & \multicolumn{2}{|c|}{ Load $(\mathrm{kN})$} & \multirow{2}{*}{$P_{\mathrm{cr}} / P_{u}(\%)$} & \multirow[b]{2}{*}{ Reserved strength $P_{u}-P_{\mathrm{cr}} / P_{\mathrm{cr}}(\%)$} \\
\hline & & & Inclined cracking $P_{\mathrm{cr}}$ & Ultimate $P_{u}$ & & \\
\hline DG1TB3 & 1.0 & & 200 & 640 & 31 & 220 \\
\hline DG2TB3 & 1.35 & 50 & 170 & 510 & 33 & 200 \\
\hline DG3TB3 & 1.7 & & 143 & 430 & 33 & 201 \\
\hline
\end{tabular}

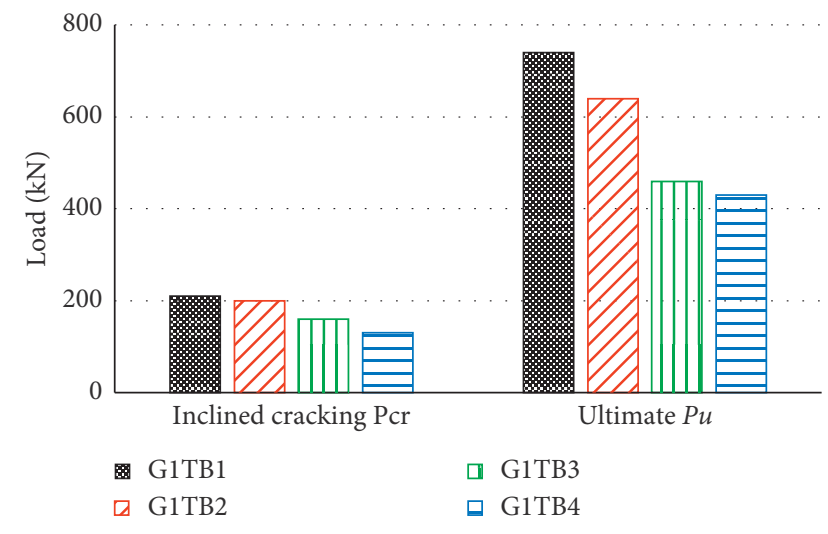

FIGURE 11: Comparison between inclined cracking loads and ultimate loads for indirectly loaded beams with different RCA.

for directly and indirectly loaded beams with different $a / d$ ratios. For beams prepared with the same RCA and $a / d$ ratio, Figure 12 shows that the directly loaded beams developed higher cracking strength and ultimate strength compared with indirectly loaded beams.

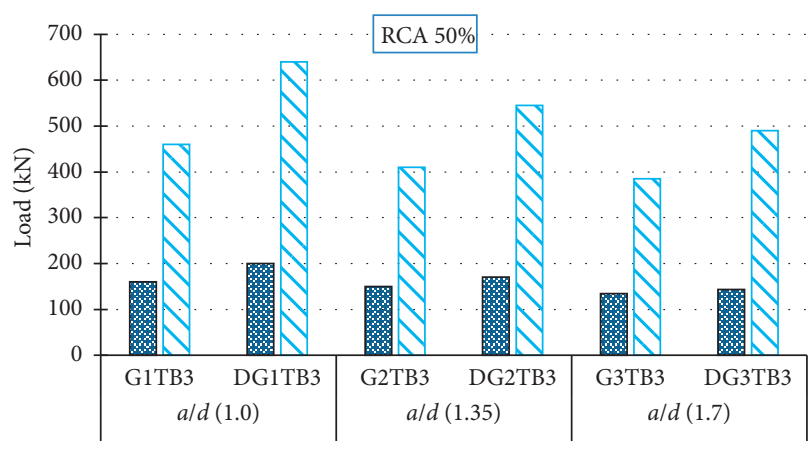

중 Cracking load Pcr

$\checkmark$ Ultimate load Pcr

FIGURE 12: Comparison between inclined cracking loads and ultimate loads of directly and indirectly loaded beams with different a/d ratios.

4.2.3. Effect of Web Reinforcement. Although the presence of vertical web reinforcement does not affect the first inclined cracking loads, it affects the crack width. Further, the ultimate load capacity is significantly affected by the existence of 
web reinforcement, as shown in Table 11 and Figure 13. For example, the presence of vertical web reinforcement in indirectly loaded flanged deep beams G1TB3S100 causes an increase in ultimate loads of about $35 \%$ as compared with beams without web reinforcement, GTB. Also, the ultimate load capacity of G1TB3S50 was increased by $48 \%$ compared with GTB. This finding complies with [21, 22]. Table 11 shows that, for the same a/d ratio, the ratio of inclined cracking to ultimate loads was $27 \%$ and $25 \%$ for the indirectly loaded flanged deep beam with shear reinforcement of G1TB3S100 and G1TB3S50, respectively.

4.2.4. Reserved Strength. The reserved strength is defined as the difference between the ultimate load and diagonal cracking load divided by the diagonal cracking load expressed as a percentage $[8,18]$. The reserved strength of the tested beams is listed in Tables 10-12. It was seen from the test results that the reserved strength of the indirectly loaded beams is lower than the reserved strength of the directly loaded beams by $9 \%$. Beams with web reinforcement exhibited 53\% reserved strength higher than those without web reinforcement. The importance of reserved strength is that a safe margin of the capacity is reserved after cracking so that no immediate failure will happen instantaneously after cracking $[8,22]$.

4.3. Deflection. From the experimental data, load-midspan deflection curves for all tested beams are shown in Figures 14-18. It can be noticed that the formation of the first major inclined crack significantly reduces beam stiffness and tends to cause a change in the slope of the curves. The higher replacement ratio of RCA results in slightly higher deflection. The increase in deflection for T-beams with increasing the replacement ratio of RCA is attributed to the lower modulus of elasticity and compressive strength of RCA compared to NA specimens. The presence of web reinforcement is also affected by reducing the midspan deflection at the same loading. The amount of deflection is increased considerably with the increase of span-effective depth ratio.

4.4. Concrete Strain. Strain in concrete was measured in several locations along the inclined strut that connects the applied load and the support as shown in Figure 6. The strain reading was profoundly affected by the presence of any crack within or near strain gauge, because the strain measurements represent the combination of concrete strain and crack width. Therefore, strain-load plots were constructed up to a load that is slightly higher the cracking load as depicted in Figures 19-24. From the experimental data, it can be concluded that the beams made with RA concrete have higher concrete strains than those made with NA. The concrete strains slightly decrease with the increase in web reinforcement. From the test results and for the same RCA ratio, the measured strain was higher when a/d increased as shown in Figures 19-22.

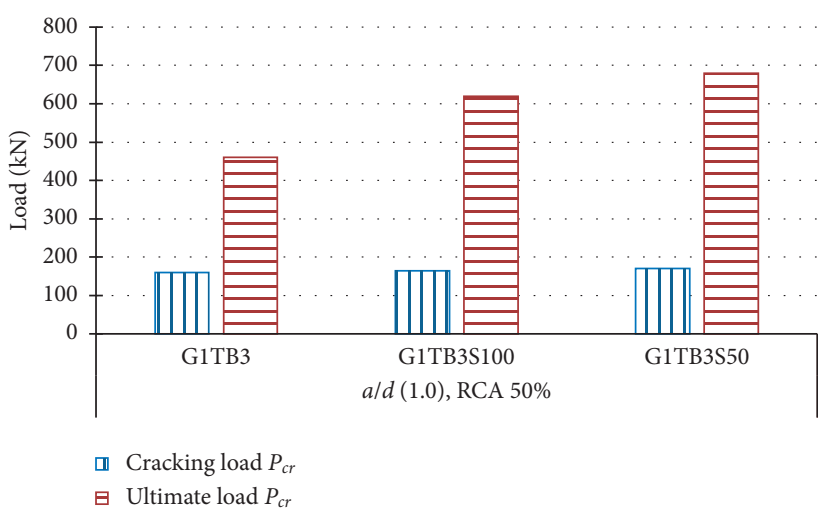

Figure 13: Comparison between inclined cracking loads and ultimate loads for indirectly loaded beams with different amount of web reinforcements.

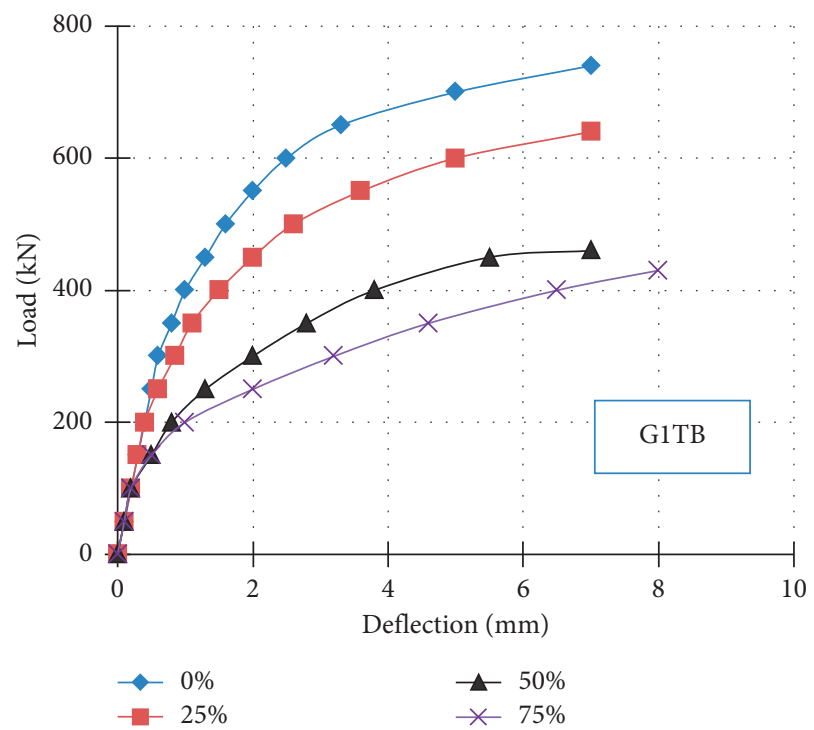

Figure 14: Load deflection curve for G1TB.

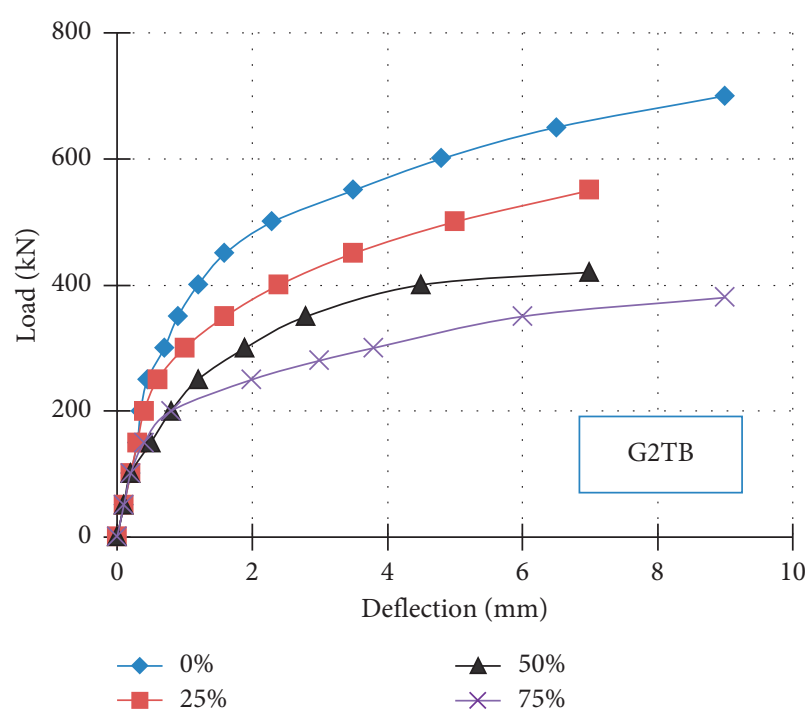

Figure 15: Load deflection curve for G2TB. 


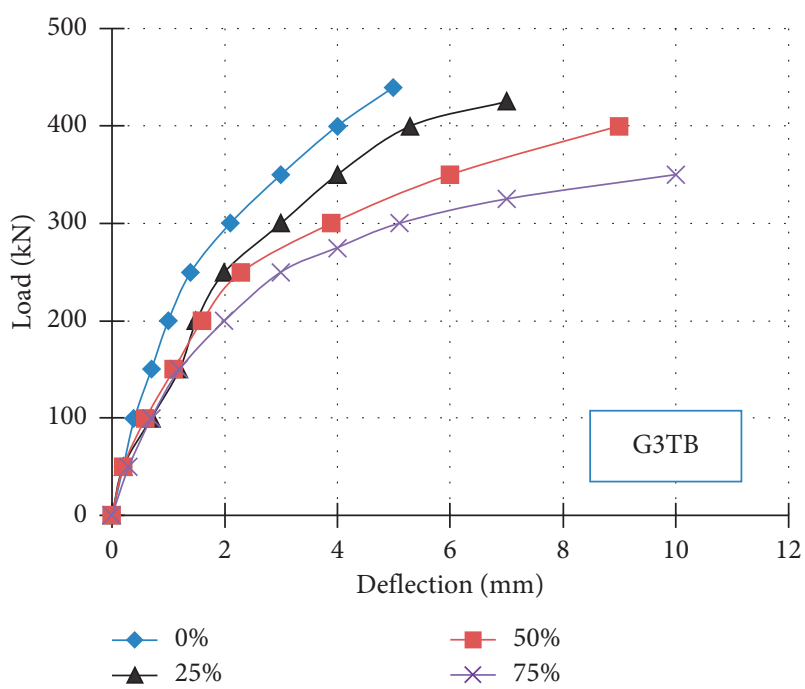

Figure 16: Load deflection curve for G3TB.

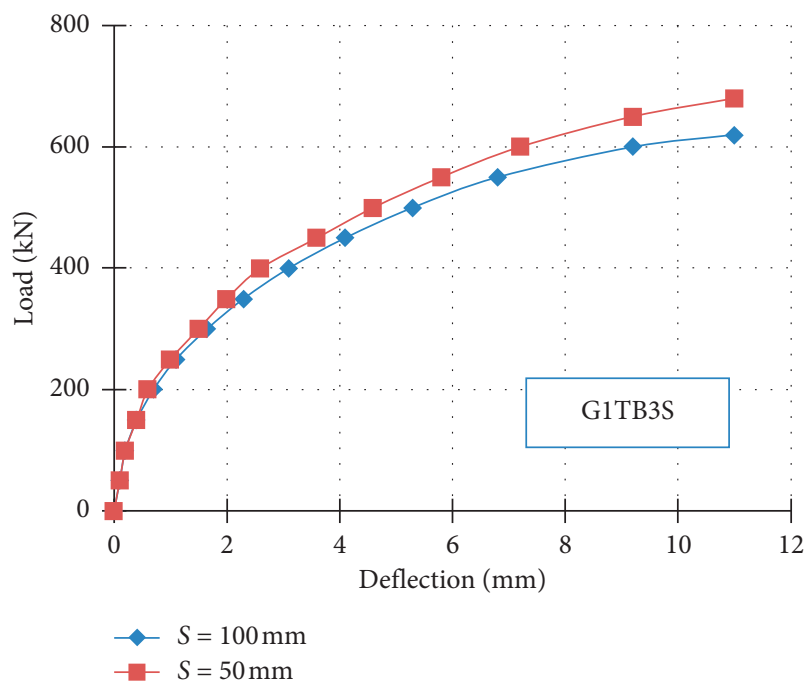

Figure 17: Load deflection curve for G1TB3S.

4.5. Inclined Crack Width. Experimental results showed that the crack width increases with the increase of the RCA replacement ratio as presented in Figure 25. This behavior is due to the lower modulus of elasticity of concrete with a higher replacement ratio. It was observed that, at the RCA ratio $(0 \%$ and $50 \%)$ and with the absence of web reinforcement, the crack width became larger as the shear span ratio $(a / d)$ increases, as illustrated in Figure 26. A comparison between the crack width values of RASCC beams and different values of web reinforcement (without stirrups, spaced at $50 \mathrm{~mm}$, and spaced at $100 \mathrm{~mm}$ ) is shown in Figure 27. It can be observed that beams without web reinforcement showed the highest crack width among the studies discussed herein. Also, the crack width showed a tendency to decrease with decreasing the spacing of the stirrups. For instance, the beam with a/dof 1.0, RCA of 50\%, and stirrups spaced at $100 \mathrm{~mm}$ showed lower crack compared to beam without web reinforcement. Furthermore, the

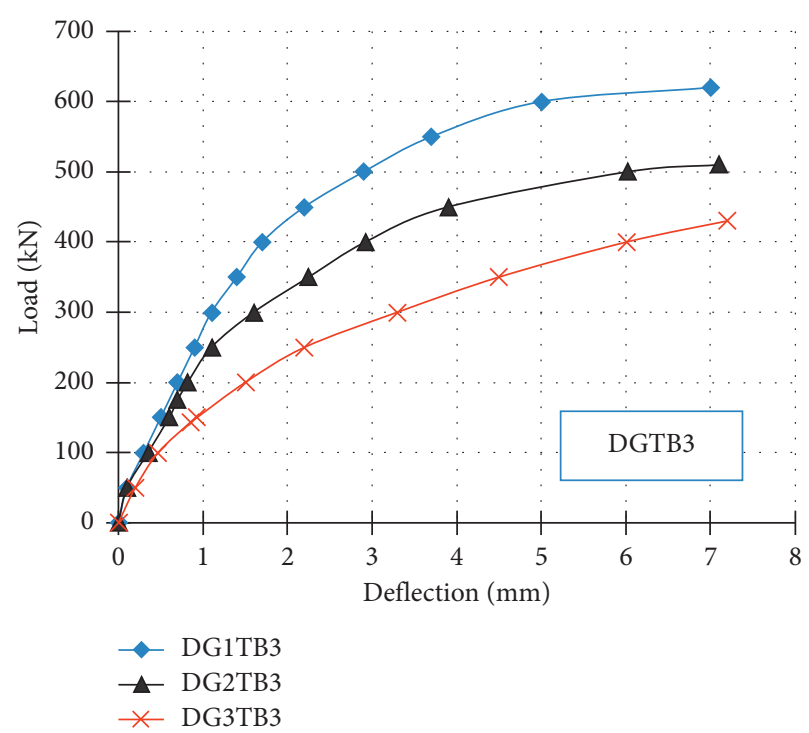

Figure 18: Load deflection curve for DGTB3.

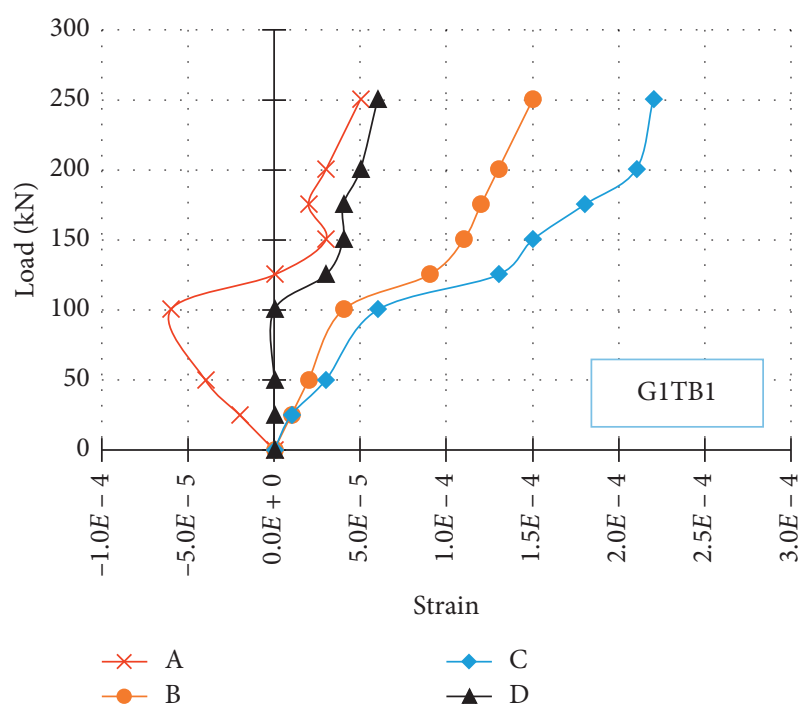

Figure 19: Strain of G1TB1.

same beam with stirrup spaced at $50 \mathrm{~mm}$ showed the smallest crack width among all the studied cases. The addition of web reinforcement causes an increase in the stiffness of the beam compared to the beam without stirrups. Furthermore, the presence of web reinforcement causes a delay in crack formation.

\section{Finite Element Analysis}

Detailed 3D finite element models of RC deep beams were implemented in this study. The FE models were created using FE commercial software package Abaqus [23] to predict ultimate shear capacity and comparing the results with experimental data. FE models were refined and calibrated using experimental data to extend them to predict other parameters that were not measured during the experimental program. The models were subjected to direct 


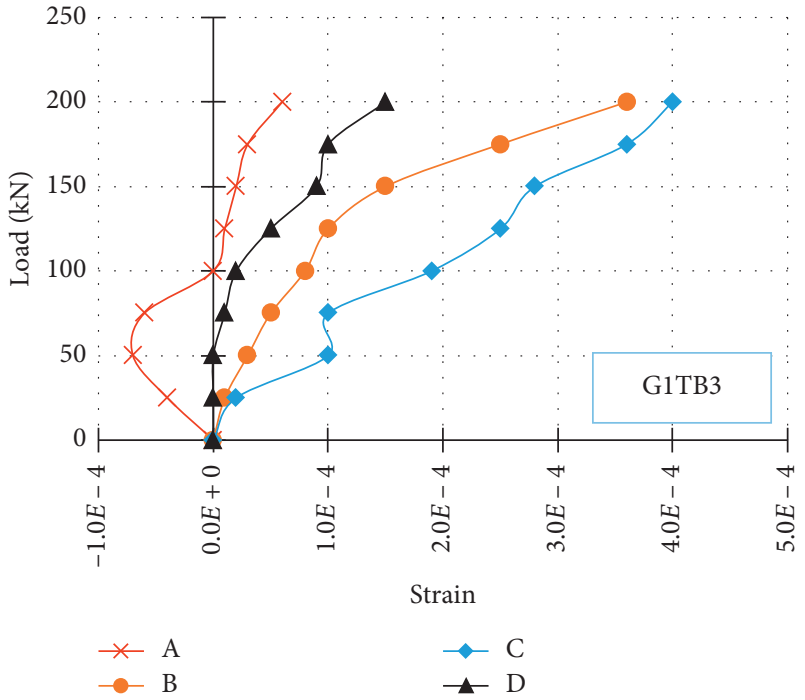

Figure 20: Strain of G1TB3.

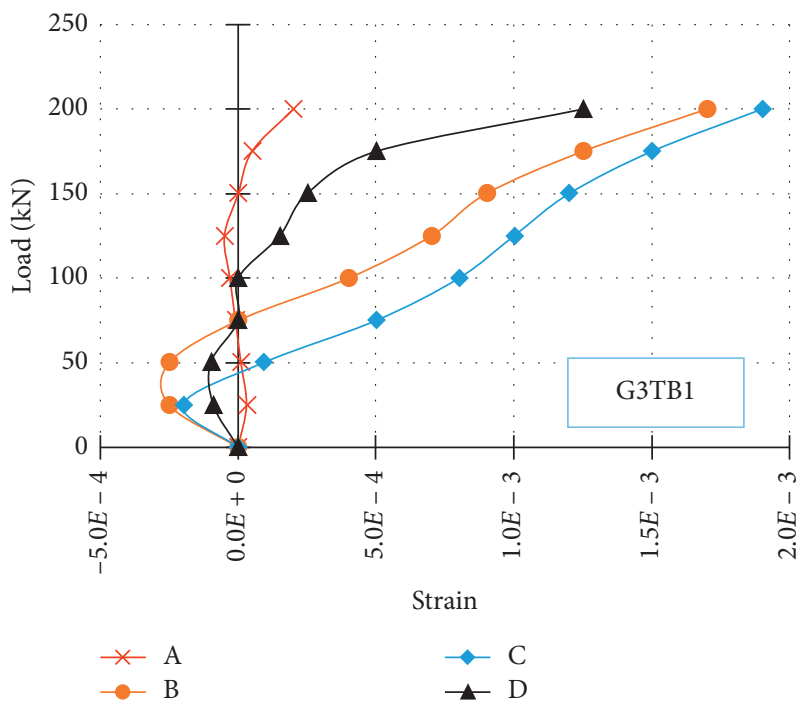

Figure 21: Strain of G3TB1.

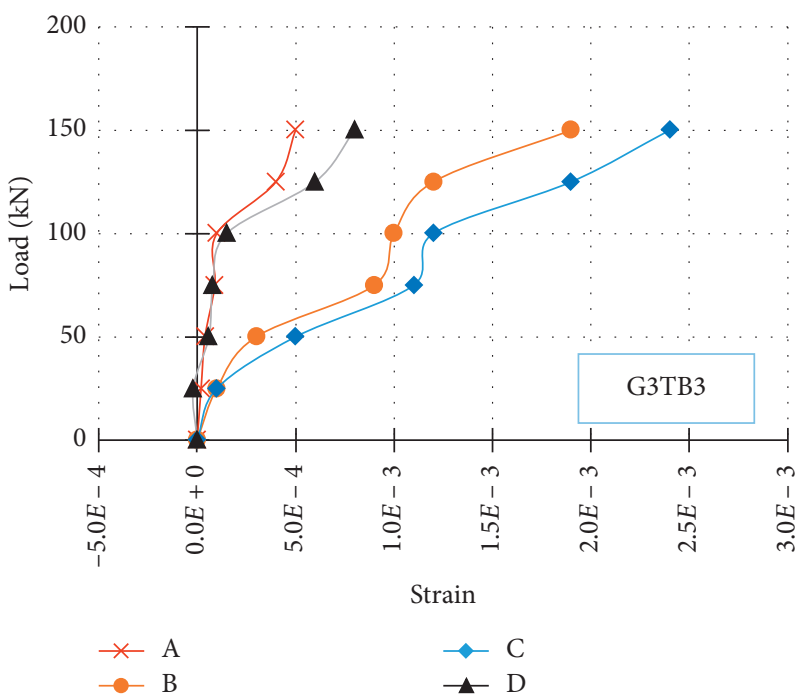

Figure 22: Strain of G3TB3.

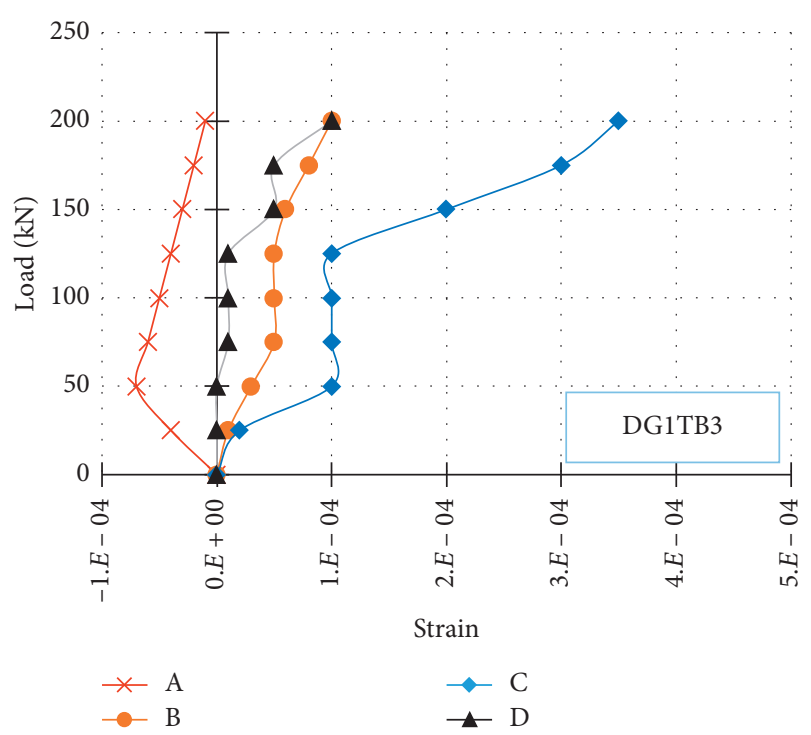

FIGURE 23: Strain of DG1TB3.

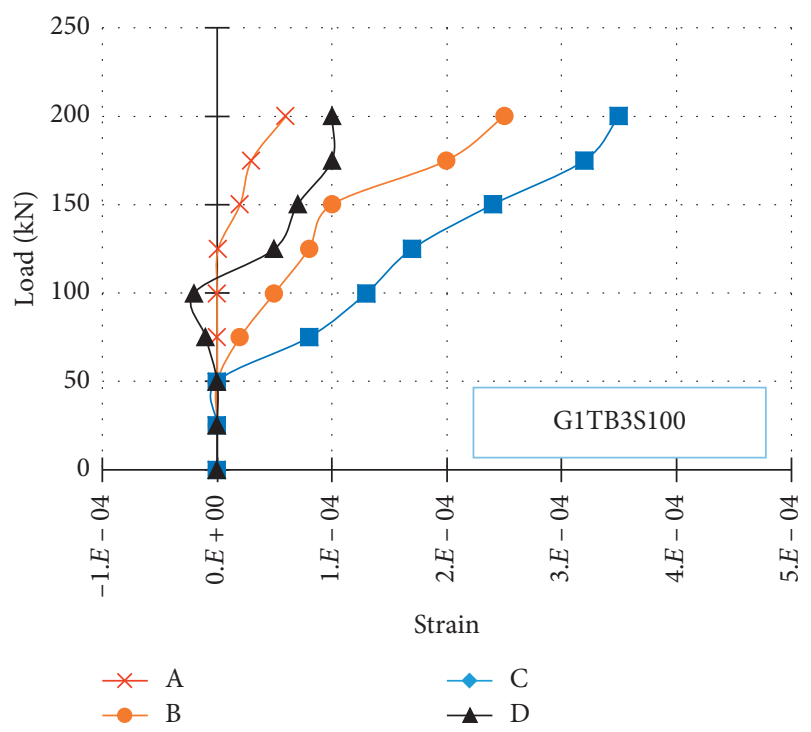

Figure 24: Strain of G1TB3S100.

and indirect loading to evaluate their shear capacity. The geometry of the FE models was taken from experimental tests. All lab-measured dimensions and reinforcement details were used in FE models as shown in Figures 2-4. The mechanical properties of concrete adopted in FE models were taken according to the experimental program. Table 9 presents the properties of the concrete used in this study with Poisson's ratio of 0.2 for concrete under uniaxial compression. Concrete damage plasticity model (CDM) was used to model concrete behavior, while the uniaxial stressstrain relation for steel bars was idealized as a bilinear curve, representing elastic-plastic behavior with strain hardening, as shown in Figure 28. In the numerical simulation, a threedimensional eight-node linear brick and reduced integration with hourglass control solid element (C3D8R) are employed to represent the concrete specimen. While three- 


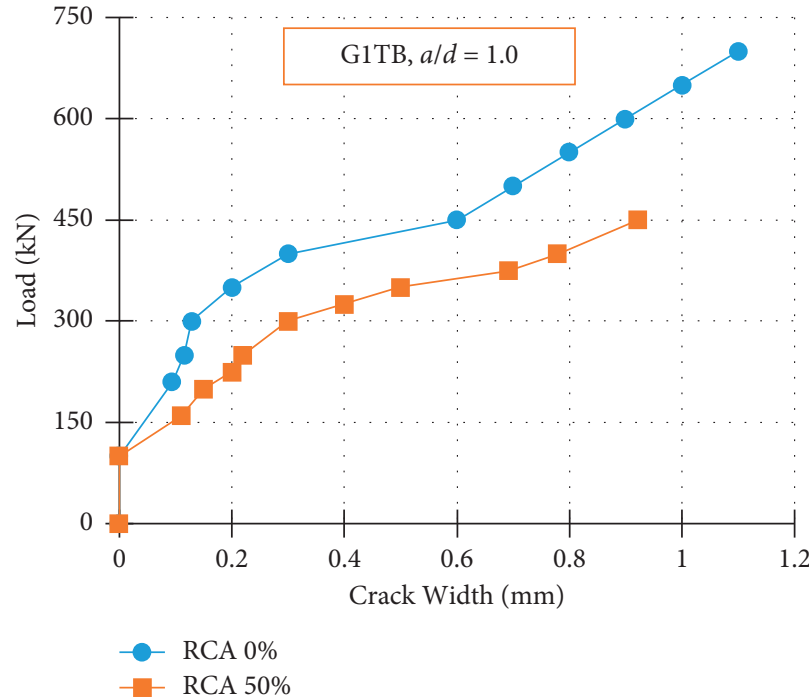

(a)

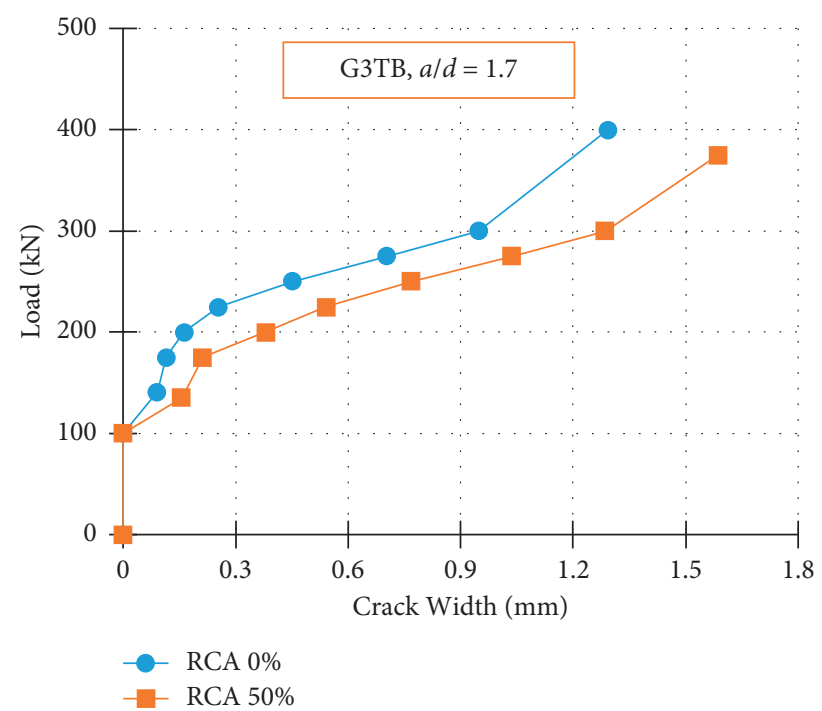

(b)

FIgURE 25: Typical crack width of indirectly loaded beams with different RCA.

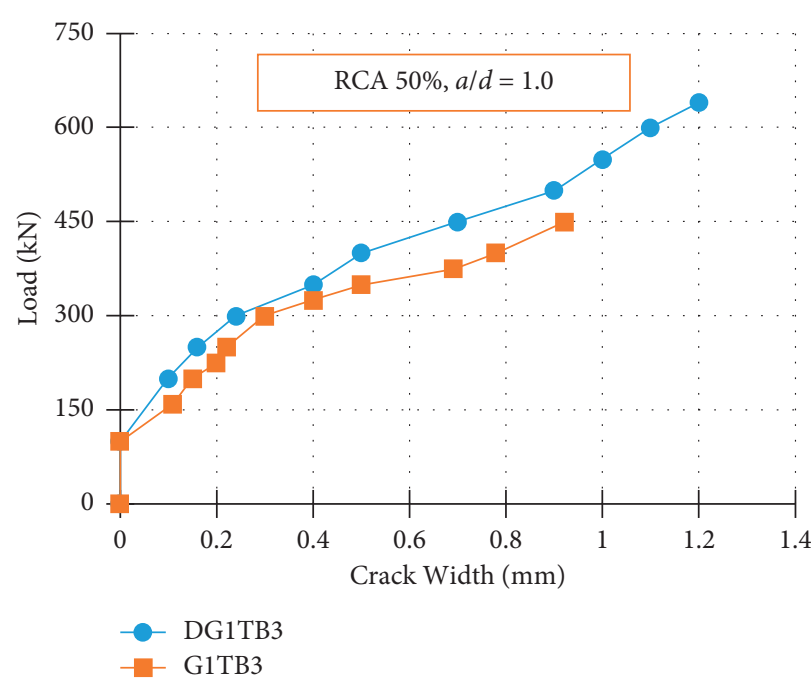

(a)

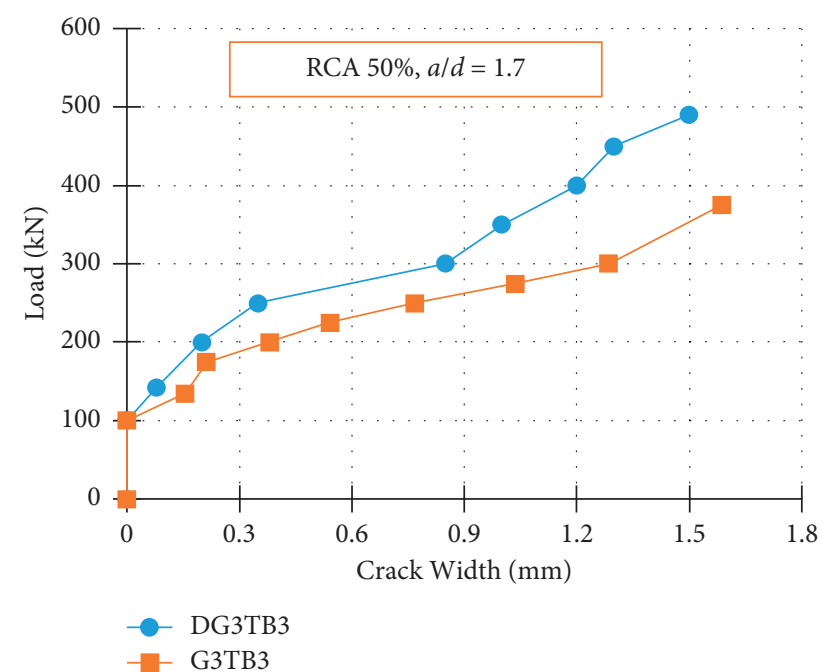

(b)

FIGURE 26: Comparison of the crack width between the directly and indirectly loaded beams with different $a / d$ ratios.

dimensional, 2-node first order truss elements (T3D2 truss) are used to model the steel reinforcements. Many research studies in the literature have recommended using these elements to model the tested beams [24-26]. A typical configuration of FE models for directly and indirectly loaded beams is presented in Figure 29. The beams were directly and indirectly loaded as in the experimental tests which are shown in Figure 7.

Mesh size is an important driver of model accuracy as well as solution time since the computational costs increase as the mesh is refined. Mesh size was the key parameter for calibration of the FE models to determine the mesh density that gives convergent results with reasonable computation time. Mesh refinement was addressed by running the model with a different mesh size and studying its effect on the midspan deflection. Mesh size versus midspan deflection is presented in Figure 30. The optimum mesh size of $25 \mathrm{~mm}$ gives good $\mathrm{FE}$ results with reasonable computational time.

\section{Comparison of STM, Experimental, and FE Results}

This section presents a comparison between the STM calculated by ACI code 318-14 and AASHTO LRFD 2012, the experimental tests, and the FEM. The ultimate load capacity, midspan deflection, strain in concrete and steel, and the crack pattern are discussed herein. 


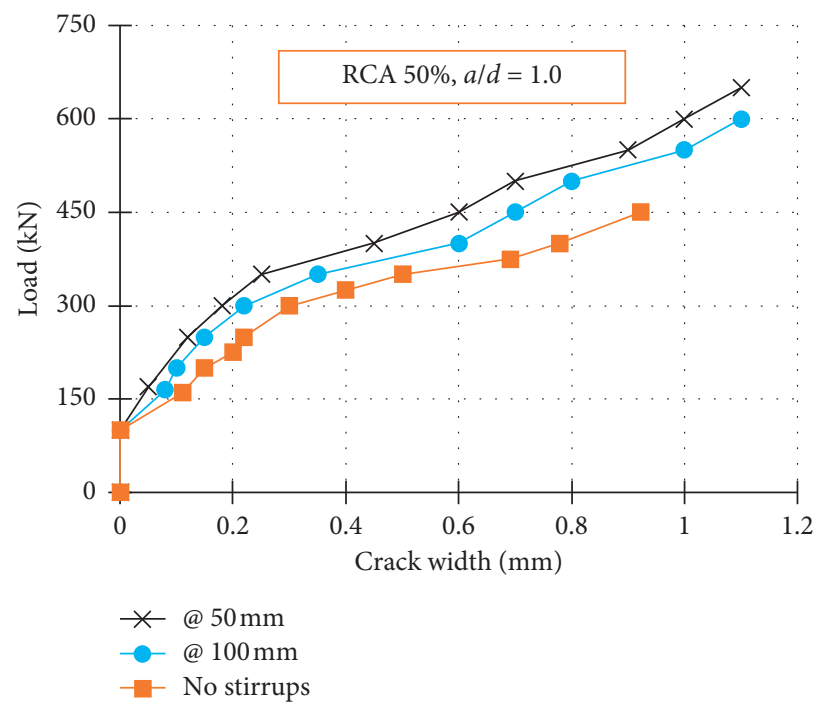

FIGURE 27: Comparison of crack width for indirectly loaded beams with different amounts of stirrup.

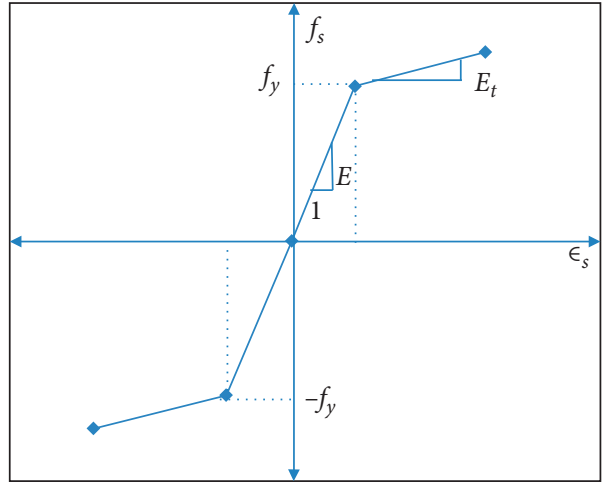

FIGURE 28: Stress-strain relation of steel reinforcement.

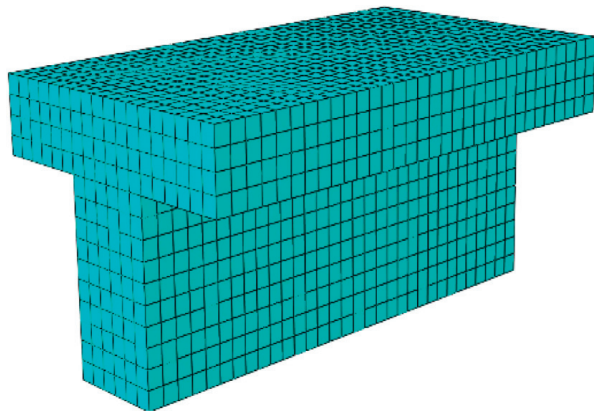

(a)

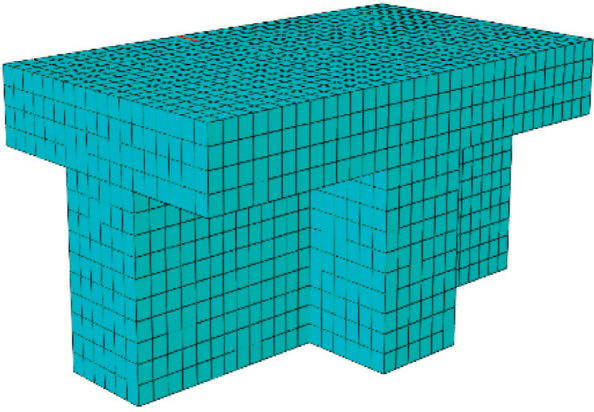

(b)

Figure 29: The FE models configuration.

6.1. Ultimate Load Capacity. The STM proposed by ACI 31814 and the AASHTO LRFD 2012 was used to predict the ultimate load capacity for deep beams, as described earlier in Section 2. STM predictions and FE results were compared with experimental data, as presented in Table 13 and Figure 31.
In Table 13 and Figure 31, STM underestimates the ultimate capacity of all beams compared with experimental results. The STM proposed by ACI 318-14 predicted an ultimate strength that is lower than experimental data by an average of $38 \%, 44 \%$, and $46 \%$ for GTB, DGTB, and GTBS, respectively. Meanwhile the STM proposed by AASHTO 


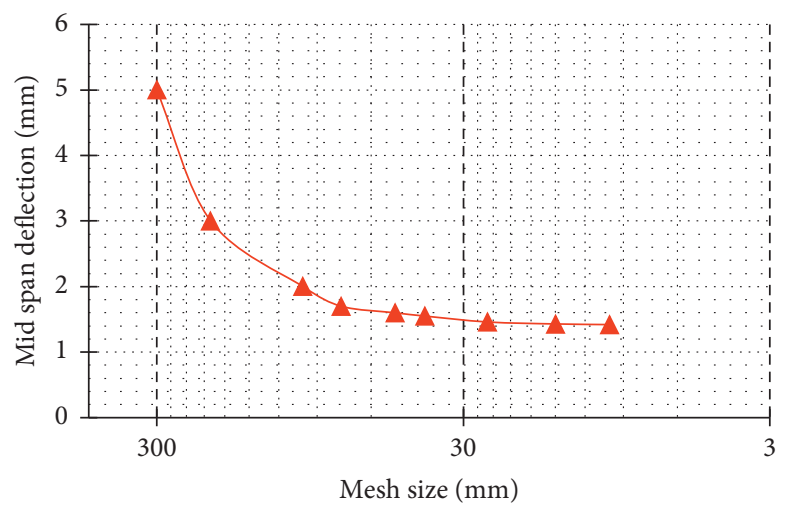

Figure 30: Mesh convergence study.

TABLE 13: Comparison of ultimate capacity of experimental, STM, and FE results.

\begin{tabular}{|c|c|c|c|c|c|c|c|}
\hline Beam SN & $\begin{array}{c}\operatorname{Exp} P_{u} \\
(\mathrm{kN})\end{array}$ & $\begin{array}{l}\mathrm{STM}_{\mathrm{ACI}} \\
(\mathrm{kN})\end{array}$ & $\mathrm{STM}_{\mathrm{ACI}}-\operatorname{Exp} / \operatorname{Exp}(\%)$ & $\begin{array}{c}\text { STM }_{\text {AASHTO }} \\
(\mathrm{kN})\end{array}$ & $\mathrm{STM}_{\text {AASHTO }}-\operatorname{Exp} / \operatorname{Exp}(\%)$ & $\begin{array}{c}F E \\
(\mathrm{kN})\end{array}$ & $F E-\operatorname{Exp} / \operatorname{Exp}(\%)$ \\
\hline \multicolumn{8}{|c|}{ Indirectly loaded RCASCC without stirrup } \\
\hline G1TB1 & 740 & 399 & -46 & 399 & -46 & 807 & 9 \\
\hline G1TB2 & 640 & 381 & -40 & 381 & -40 & 710 & 11 \\
\hline G1TB3 & 460 & 348 & -24 & 348 & -24 & 506 & 10 \\
\hline G1TB4 & 430 & 307 & -29 & 307 & -29 & 469 & 9 \\
\hline G2TB1 & 700 & 332 & -53 & 248 & -65 & 693 & 5 \\
\hline G2TB2 & 550 & 317 & -42 & 237 & -57 & 594 & 8 \\
\hline G2TB3 & 420 & 290 & -42 & 216 & -57 & 449 & 7 \\
\hline G2TB4 & 380 & 255 & -33 & 191 & -50 & 410 & 8 \\
\hline G3TB1 & 440 & 278 & -37 & 156 & -65 & 453 & 3 \\
\hline G3TB2 & 430 & 265 & -38 & 149 & -65 & 447 & 4 \\
\hline G3TB3 & 400 & 242 & -40 & 136 & -66 & 428 & 7 \\
\hline G3TB4 & 350 & 214 & -39 & 120 & -66 & 378 & 8 \\
\hline \multicolumn{8}{|c|}{ Indirectly loaded RCASCC with different amounts of web reinforcement } \\
\hline G1TB3S100 & 620 & 348 & -44 & 348 & -44 & 682 & 10 \\
\hline G1TB3S50 & 680 & 348 & -49 & 348 & -49 & 762 & 12 \\
\hline \multicolumn{8}{|c|}{ Directly loaded without stirrup and with $50 \%$ of RCA } \\
\hline DG1TB3 & 620 & 348 & -44 & 348 & -44 & 682 & 10 \\
\hline DG2TB3 & 510 & 290 & -43 & 216 & -58 & 571 & 12 \\
\hline DG3TB3 & 430 & 242.0 & -44 & 136 & -68 & 469 & 9 \\
\hline
\end{tabular}

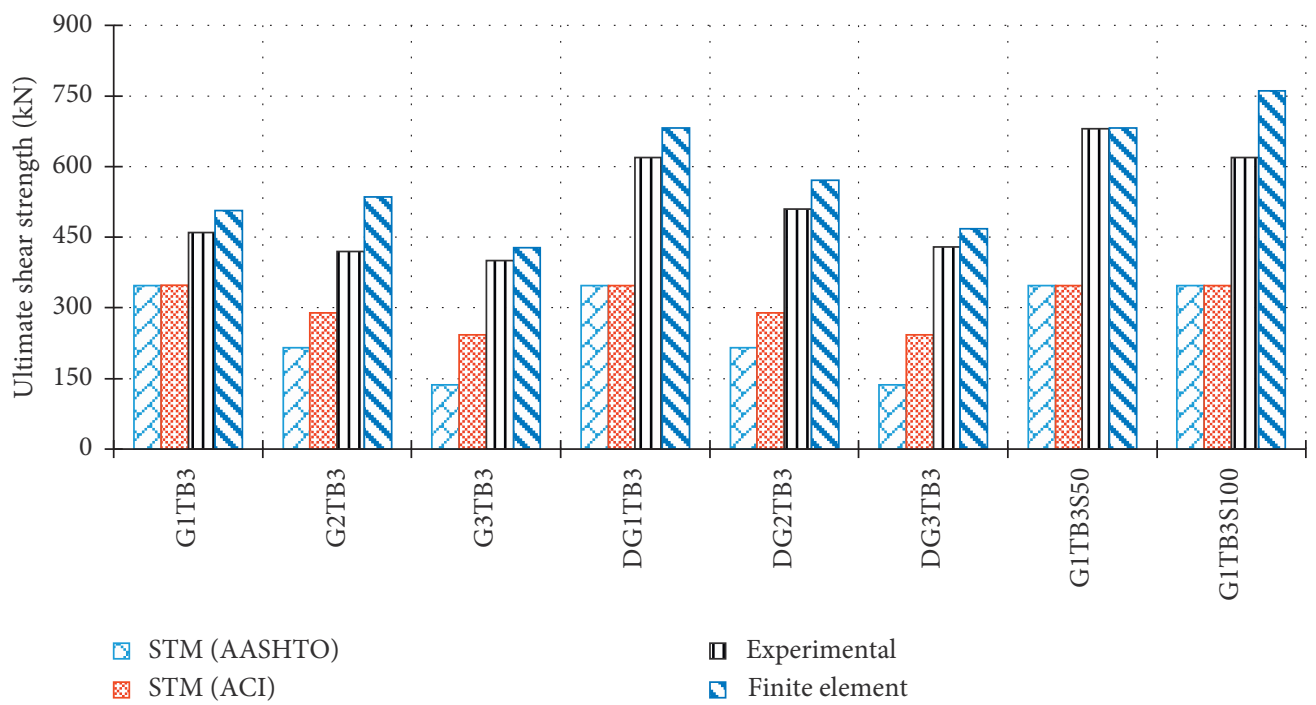

FIGURE 31: Comparison of ultimate strength predicted by STM, experimental, and FEM results. 


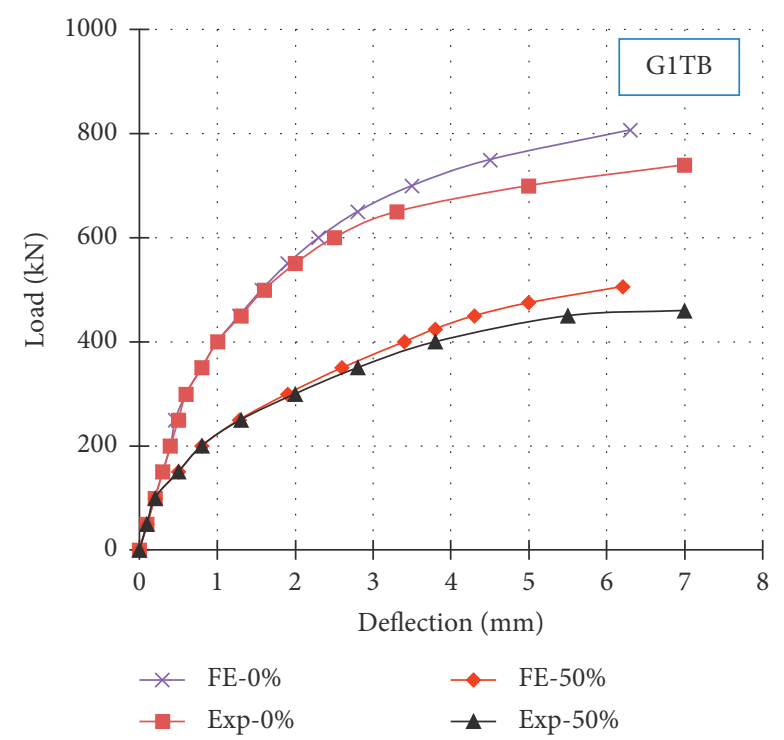

FIgURE 32: Load midspan deflection curves for indirectly loaded beams.

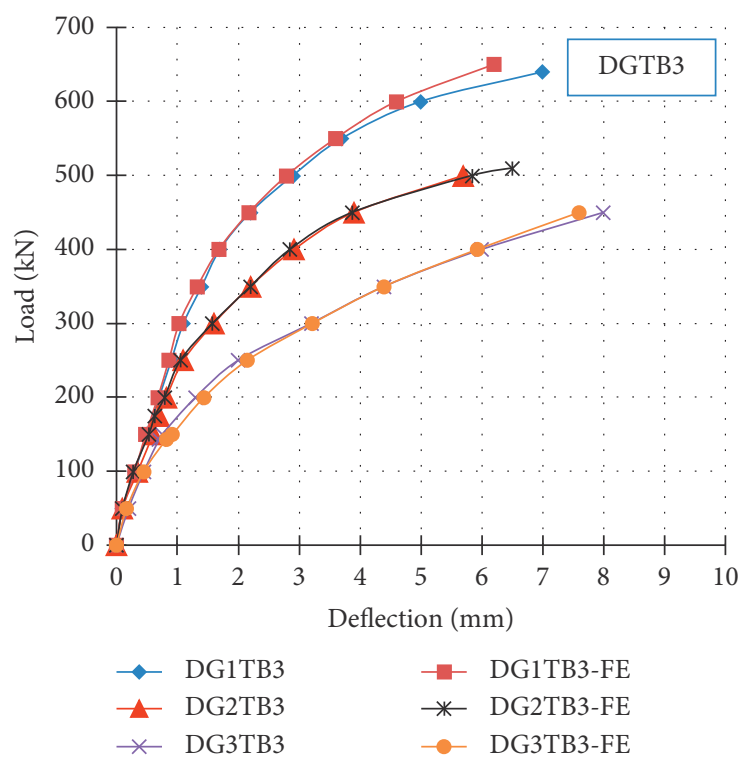

FIGURE 33: Load midspan deflection curves for directly loaded beams.

LRFD 2012 predicted an ultimate strength that is lower than experimental data by an average of $53 \%, 57 \%$, and $47 \%$ for GTB, DGTB, and GTBS, respectively.

Generally, the FE models predicted an ultimate capacity that is slightly higher than the experimental result. This behavior is due to the variation in the actual material composition, assumed to be homogenous in the FE models. However, the FE predictions showed good agreement with experimental data. FE models predicted an ultimate strength that is $7 \%, 10 \%$, and $11 \%$ higher than the experimental data for GTB, DGTB, and GTBS, respectively.

It can be seen from Figure 31 that the predictions yielded by the STM method are more conservative than the experimental and FE results. The STM can be used to estimate a safer ultimate shear capacity. Even though the experimental tests showed that the directly loaded beams are stronger than indirectly loaded beams, the STM was unable to predict such results. The experimental data were used to refine and calibrate the FE model. Good agreement was achieved between FE predictions and experimental results.

6.2. Midspan Deflection. Figure 32 illustrates the load midspan deflection curves for experimental and FE results of the indirectly loaded first group of beams, G1TB. Load deflection curves for experimental and FE results of the directly loaded group, DGTB, are presented in Figure 33. It 


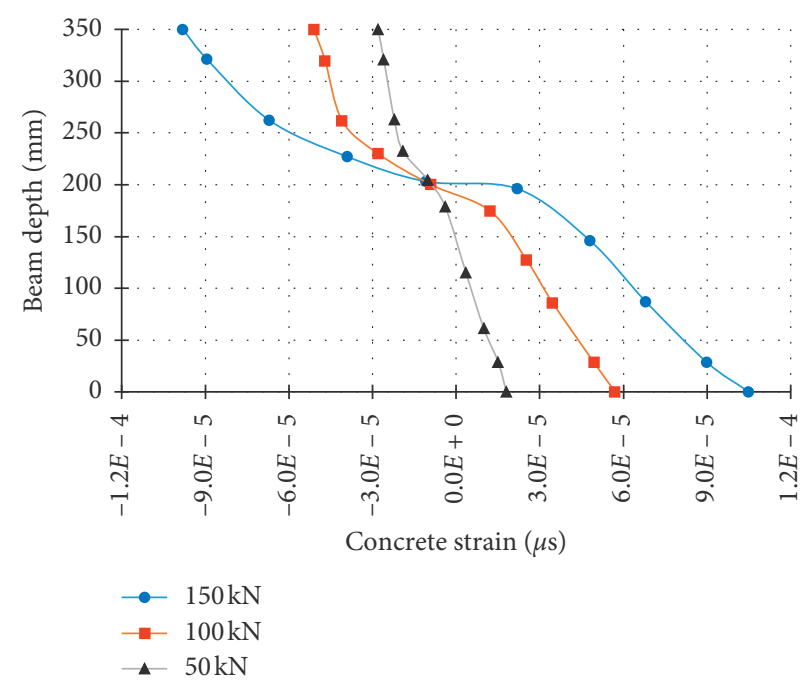

FIGURE 34: FE-predicted midspan concrete strain distribution through the depth.

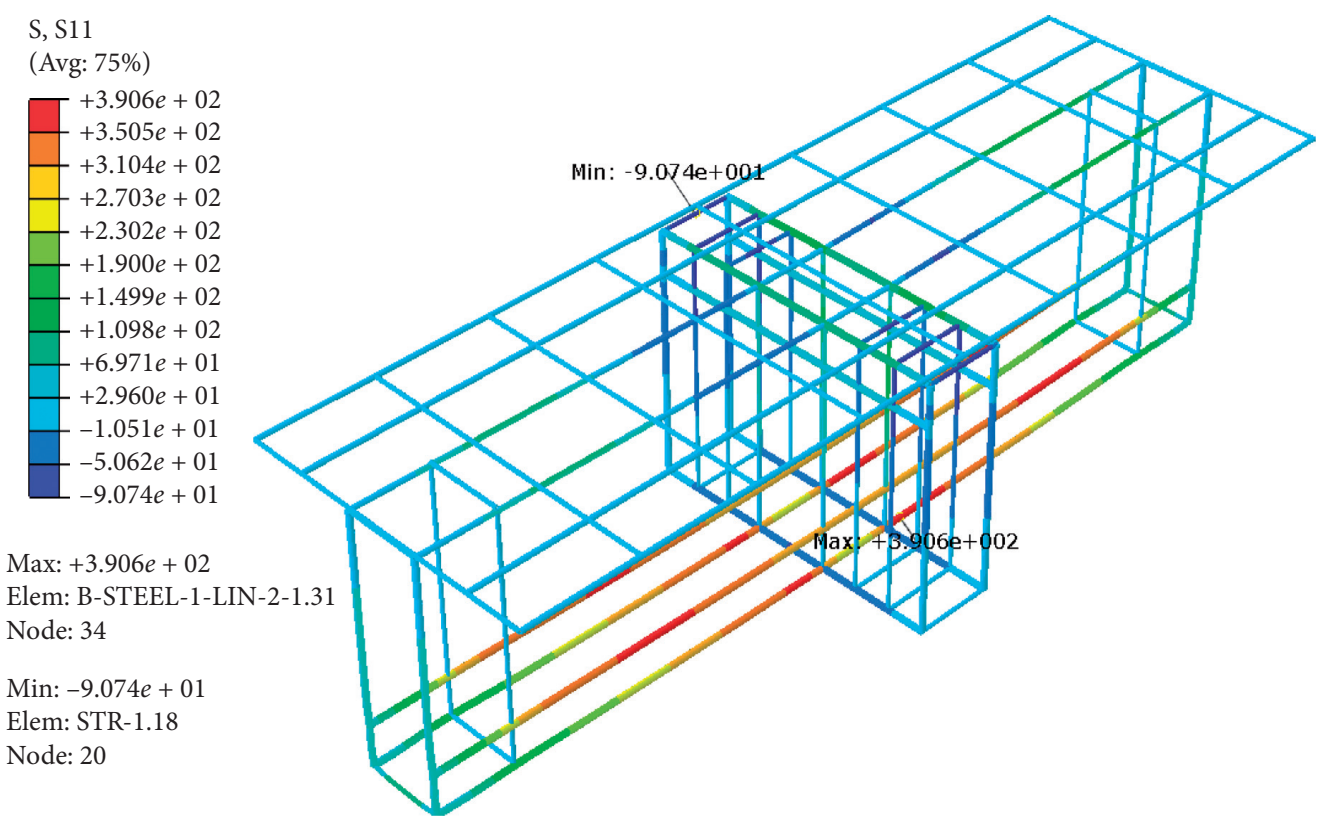

FIGURE 35: Finite element stress for G1TB3.

was observed from both Figures that the deflection predicted by FE models was slightly less than the corresponding measured deflection from experimental data. Such a response is because the FE models are stiffer than the actual beams as the FE models do not account for any variation in the actual material composition.

However, the numerical data and experimental results showed very good agreement. At different loading stages, the predicted deflection from the FE models was lower than the corresponding deflection from the experiment data. For instance, when the applied load reached $65 \%$ of the failure load, which represents the applied service load as recommended by $[3,25]$, the numerical models underestimated the deflection by an average of $6 \%$ for indirectly loaded beams and $1 \%$ for directly loaded deep beams compared with the experimental data. Cracking patterns obtained from the finite element analysis showed reasonable agreement with the failure modes obtained experimentally.

6.3. Strain in Concrete and Steel Reinforcement. FE-predicted midspan concrete strain distribution through the depth of the beam is presented in Figure 34. Nonlinear strain distribution through the depth of the beam is observed even at early loading stages. This finding confirms the fact that the nonlinear strain distribution through the depth is because of the significant shear deformation. The stresses in steel reinforcement of a selected beam, G1TB3, are shown in 

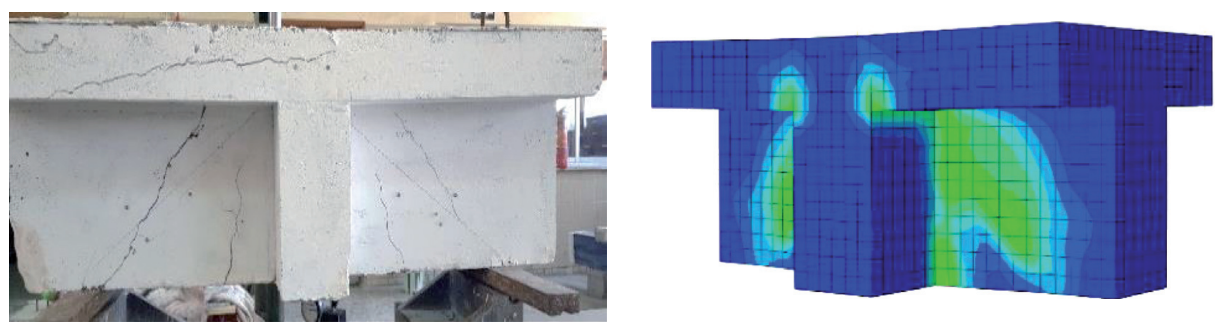

FIGURE 36: Strain and crack patterns at failure load for GTB.
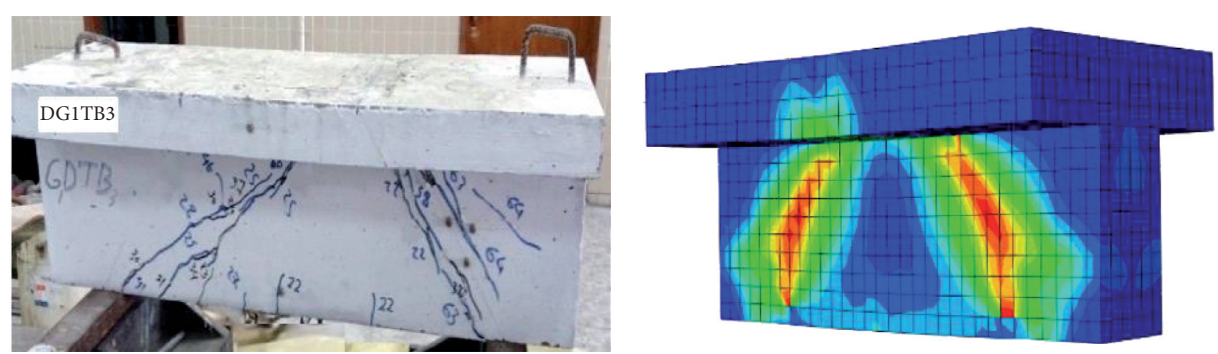

FIgURE 37: Strain and crack patterns at failure load for DGTB.

Figure 35. From this figure, it can be noticed that the maximum stress did not reach the yield strength of the main reinforcement, which was made on purpose to achieve the failure of the compression strut before yielding the steel.

Figures 36 and 37 show the experimental strain distribution along the beams. From these figures, it is indicated that the maximum strain measurements occurred along the load path where the inclined crack has occurred.

Stresses and strains in the main reinforcement were increased with the decrease of a/d because of the higher contribution of arch action.

At the same load level, the increase in RCA content leads to a rise in both stresses and strains in steel reinforcement. This response is because the beam made with a higher RCA has a lower stiffness and earlier cracks initiation, so the load transfer to steel reinforcement will occur earlier.

6.4. Crack Pattern. The crack in concrete initiated when the principal tensile stress developed due to the applied load exceeds the tensile strength of concrete. The appearance of the cracks reflects the failure mode for the beams. Cracking patterns obtained from the finite element analysis showed reasonable agreement with the failure modes obtained experimentally. Figures 36 and 37 show the experimental and FE cracking pattern for indirectly and directly loaded beams, respectively. The number of cracks and their width were increased with increasing the RCA ratio due to the lower concrete stiffness. The addition of web reinforcement leads to an increase in the load-carrying capacity of beams.

In general, flexural cracks occur at midspan at early loading stages. When applied loads increased, vertical flexural cracks spread horizontally, starting from midspan toward the supports. At a higher applied load, diagonal cracks appear. Increasing the applied loads induces additional diagonal and flexural cracks. Finally, compressive cracks appear at nearly the last applied load steps.

\section{Summary and Conclusions}

In this research, seventeen deep beams were prepared and tested to study the shear strength of directly and indirectly loaded flanged self-compacted RC deep beams containing recycled concrete as coarse aggregate. Five groups were prepared, in which four groups are indirectly loaded while the fifth group is directly loaded. The parameters considered in this study are the replacement ratio of RCA, shear span-to-effective depth $(a / d)$ ratio, and the web reinforcement. Test results showed that all beams failed in shear with no local failure under load application nor over supports. Also, the main bars properly functioned to prevent any anchorage failure. Therefore, shear failure due to diagonal cracking results in splitting the beams along the diagonal crack. The crack pattern formed a simple strut configuration with a triangle shape connecting the load application area with the two supports.

It was observed from the experimental results for both, directly and indirectly, loaded beams that the compressive strength, modulus of elasticity, and splitting tensile strength were reduced by the increase of the RCA replacement ratio. For instance, the RCA replacement ratio increased to $25 \%$, $50 \%$, and $75 \%$, and the compressive strength decreased by $44 \%, 13 \%$, and $23 \%$, respectively. Also, the splitting tensile strength decreased by $1 \%, 13 \%$, and $21 \%$, respectively, and the modulus of elasticity reduced by $2 \%, 6 \%$, and $12 \%$, respectively. As a result, the measured deflection was higher when the RCA was increased. Also, a higher strain was observed as the RCA was increased. The cracking and ultimate capacities were decreased with the increase of the RCA replacement ratio. For example, in beams of the first 
group, G1TB, with RCA of 25\%, 50\%, and 75\%, the cracking load was decreased by $5 \%, 24 \%$, and $38 \%$, while the ultimate load was decreased by $14 \%, 38 \%$, and $42 \%$.

The cracking and ultimate loads for indirectly loaded beams with RCA of $50 \%$ showed an increase of $19 \%$ and $15 \%$, respectively, which was obtained by reducing $a / d$ ratio from 1.7 to 1.0 . Further, the increase in cracking and ultimate loads was $7 \%$ and $10 \%$ by reducing $a / d$ from 1.35 to 1.0 , while for directly loaded beams with $50 \%$ of replacement, an increase of $29 \%$ and $33 \%$ of the cracking and ultimate loads was observed by reducing a/d from 1.7 to 1.0 . Moreover, the increase in the cracking and ultimate loads was $15 \%$ and $20 \%$ with a reduction in $a / d$ ratio from 1.35 to 1.0 .

Although the presence of vertical web reinforcement does not significantly affect the first inclined cracking loads, it increases the ultimate load capacity by $48 \%$ and $35 \%$ for beams with web reinforcement spaced at $50 \mathrm{~mm}$ and $100 \mathrm{~mm}$, respectively. The existence of web reinforcement leads to slightly lower deflection and small cracking width.

STM ultimate strength predicted by ACI 318-14 and AASHTO LRFD 2012 was lower than the experimental results for all beams. Furthermore, the ACI318-14 and AASHTO LRFD 2012 predicted identical capacity for the case of $a / d=1.0$. However, as $a / d$ changed to 1.35 and 1.7 , the calculated capacity by AASHTO LRFD 2012 was $25 \%$ and $44 \%$ lower than the capacity predicted by ACI $318-14$, respectively. This is because the concrete effective compressive stress in the struts calculated by ACI 318-14 does not account for the change in a/d ratio in contrast with AASHTO LRFD 2012 as shown in Table 1. STM underestimates the ultimate capacity of all beams compared with experimental results. The STM proposed by ACI318-14 predicted a strength that is lower than experimental data by an average of $38 \%, 44 \%$, and $46 \%$ for GTB, DGTB, and GTBS, respectively. Meanwhile, STM proposed by AASHTO LRFD 2012 predicted a strength that is lower than experimental data by an average of $52 \%, 44 \%$, and $46 \%$ for GTB, DGTB, and GTBS, respectively. FE predictions showed good agreement with experimental data. FE models predicted an ultimate strength that is $7 \%, 10 \%$, and $11 \%$ higher than the experimental data for GTB, DGTB, and GTBS, respectively. At different loading stages, the predicted deflection from the FE models was lower than the corresponding deflection from the experiment data. For instance, when the applied load reached $65 \%$ of the failure load, the numerical models underestimated the deflection by an average of $6 \%$ for indirectly loaded beams and $2 \%$ for directly loaded deep beams compared with experimental data. Cracking patterns obtained from the finite element analysis showed reasonable agreement with the failure modes obtained experimentally.

From the experimental data, indirectly loaded flanged deep beams are weaker than directly loaded deep beams; this is due to the lower arch action developed in indirectly loaded RC deep beams. Based on test results, the ultimate capacity of directly loaded deep beams was about $23 \%$ higher than the ultimate capacity of indirectly loaded beams. This modification factor, extracted from experimental data, can be applied to the STM method to account for different loading conditions as STM does not account for such effect.

\section{Data Availability}

All the data supporting the results reported in this research article are available at the University of Basrah, Iraq. The data are also available from the corresponding author upon request.

\section{Conflicts of Interest}

The authors declare that they have no conflicts of interest regarding the publication of this paper.

\section{References}

[1] K. N. Rahal and Y. T. Alrefaei, "Shear strength of longitudinally reinforced recycled aggregate concrete beams," Engineering Structures, vol. 145, pp. 273-282, 2017.

[2] G. Wardeh and E. Ghorbel, "Shear strength of reinforced concrete beams with recycled aggregates," Advances in Structural Engineering, vol. 22, no. 8, pp. 1938-1951, 2019.

[3] C. Roy, T. U. Mohammed, and R. Hasan, "Experimental analysis on self-compacting concrete (SCC) made with locally available materials incorporating different W/C ratio," in Proceedings of International Conference on Planning, Architecture and Civil Engineering, Rajshahi, Bangladesh, February 2019.

[4] V. Revilla-Cuesta, M. Skaf, F. Faleschini, J. M. Manso, and V. Ortega-López, "Self-compacting concrete manufactured with recycled concrete aggregate: an overview," Journal of Cleaner Production, vol. 262, Article ID 121362, 2020.

[5] ACI Committee, Building Code Requirements for Structural Concrete (ACI 318-14) and Commentary, American Concrete Institute, Indianapolis, IN, USA, 2014.

[6] AASHTO, AASHTO LRFD Bridge Design Specifications Customary US Units, American Association of State Highway and Transportation Officials, Washington, DC, USA, 2012.

[7] A. Razzaq, K. Saleem, and S. F. Jebur, "Experimental verification of strut and tie method for reinforced concrete deep beams under various types of loadings," Journal of Engineering and Sustainable Development, vol. 21, no. 6, pp. 39-55, 2017.

[8] Y. Lafta, K. Ye, and K. Ye, "Experimental investigation of shear behavior of deep rc t-beams under indirect loading," British Journal of Applied Science \& Technology, vol. 15, no. 5, pp. 1-19, 2016.

[9] Iraqi Standards, Ordinary Portland Cement; No. 5/1984, Ministry of Housing and Construction, Baghdad, Iraq, 2004.

[10] ASTM, ASTM C150: Standard Specification for Portland Cement, ASTM International, Philadelphia, PA, USA, 2001.

[11] ASTM, ASTM C109-Standard Test Method for Compressive Strength of Hydraulic Cement Mortars, ASTM International, West Conshohocken, PA, USA, 2008.

[12] British Standards Institution, Cement Composition, Specifications and Conformity Criteria For Common Cements, British Standards Institution, London, UK, 2011.

[13] ASTM, Standard Specification for Concrete Aggregates, ASTM, West Conshohocken, PA, USA, 2008.

[14] ASTM, Standard Specification for Chemical Admixtures for Concrete, American Society for Testing Materials, Philadelphia, PA, USA, 2004.

[15] ASTM, Standard Specification for Deformed And Plain Carbon-Steel Bars for Concrete Reinforcement: A615/A615M-04b, ASTM, Philadelphia, PA, USA, 2004. 
[16] J. Jin, Properties of mortar for self-compacting concrete, Ph.D. Thesis, University of London, London, UK, 2002.

[17] Association House, Guidelines for Self-Consolidating Concrete, Association House, London, UK, 2005.

[18] C. Pellegrino and C. Modena, "Fiber reinforced polymer shear strengthening of reinforced concrete beams with transverse steel reinforcement," Journal of Composites for Construction, vol. 6, no. 2, pp. 104-111, 2002.

[19] S. Fereig and K. Smith, "Indirect loading on beams with short shear spans," ACI Journal Proceeding, vol. 74, no. 5, pp. 220-222, 1977.

[20] ACI-ASCE Committee, "The shear strength of reinforced concrete members," ACI Journal Proceedings, vol. 70, no. 7, pp. 1091-1187, 1973.

[21] G. A. Rao, K. Kunal, and R. Eligehausen, "Shear strength of $\mathrm{RC}$ deep beams," in Proceedings of the 6th International Conference on Fracture Mechanics of Concrete and Concrete Structures, Catania, Italy, June 2007.

[22] A. A. M. Ali and R. Lazim Hussein, "Experimental study of the behavior of deep beams using light-weight structural leca concrete," IJIRST, vol. 5, no. 1, pp. 428-436, 2016.

[23] Abaqus, Computer software, Dassault Systèmes, Vélizy-Villacoublay, France, 2017.

[24] M. J. A. Albraheemi, W. G. Davids, A. Schanck, and S. Tomlinson, "Evaluation and rating of older non-composite steel girder bridges using field live load testing and nonlinear finite element analysis," Bridge Structures, vol. 15, no. 1-2, pp. 27-41, 2019.

[25] Dr. Yousif, J. Lafta, H. K. Hussain, and M. R. Daham, Finite Element Analysis of Simply Supported Deep Beam Using Abaqus, Basrah University, Basrah, Iraq, 2020.

[26] T. Alhussein, H. Amer, and J. A. S. Khudhair, "Shear strength of directly and indirectly loaded rectangular self-compacted reinforced concrete deep beams containing recycled concrete as coarse aggregate," Anbar Journal of Engineering Sciences, vol. 8, no. 3, pp. 212-220, 2020. 